\title{
GROUNDWATER PROTECTION MODEL AT NIAGARA USING GIS TOOLS
}

\author{
By \\ Mafruha Ahmed \\ B.Eng. (Civil), Khulna Engineering University, 2000
}

\begin{abstract}
A project report
presented to Ryerson University in partial fulfillment of the requirements for the degree of Master of Engineering in the Program of Civil Engineering
\end{abstract}

Toronto, Ontario, Canada, 2005

(C) Mafruha Ahmed, 2005 


\section{UMI Number: EC53000}

\section{All rights reserved \\ INFORMATION TO USERS}

The quality of this reproduction is dependent upon the quality of the copy submitted. Broken or indistinct print, colored or poor quality illustrations and photographs, print bleed-through, substandard margins, and improper alignment can adversely affect reproduction.

In the unlikely event that the author did not send a complete manuscript and there are missing pages, these will be noted. Also, if unauthorized copyright material had to be removed, a note will indicate the deletion.

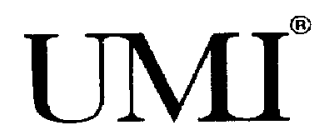

UMI Microform EC53000

Copyright 2008 by ProQuest LLC

All rights reserved. This microform edition is protected against unauthorized copying under Title 17, United States Code.

ProQuest LLC

789 East Eisenhower Parkway

P.O. Box 1346

Ann Arbor, MI 48106-1346 


\section{AUTHOR'S DECLARATION}

I hereby declare that I am the sole author of this project report,

I authorize Ryerson University to lend this project report to other institutions or individuals for the purpose of scholarly research,

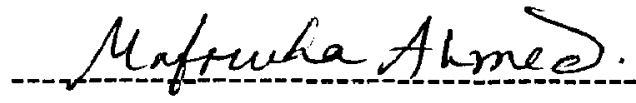

Mafruha Ahmed

Department of Civil Engineering

Ryerson University

I further authorize Ryerson University to reproduce this project report by photocopying or by other means, in total or in part, at the request of their institutions or individuals for the purpose of scholarly research.

Mafruha Amned.

Mafruha Ahmed

Department of Civil Engineering

Ryerson University 


\section{BORROWER'S}

Ryerson University requires the signatures of all persons using or photocopying this project report. Please sign below and give address and date.

\begin{tabular}{|c|c|c|c|}
\hline Name & Address & Signature & Date \\
\hline & & & \\
\hline & & & \\
\hline & & & \\
\hline & & & \\
\hline & & & \\
\hline & & & \\
\hline & & & \\
\hline & & & \\
\hline & & & \\
\hline & & & \\
\hline & & & \\
\hline & & & \\
\hline & & & \\
\hline & & & \\
\hline & & & \\
\hline & & & \\
\hline & & & \\
\hline & & & \\
\hline & & & \\
\hline
\end{tabular}




\section{Ryerson University \\ School of Graduate Studies}

The undersigned certify that they have read, and recommend to the School of Graduate Studies for acceptance, a project entitled "Groundwater Protection Model at Niagara Using GIS Tools" submitted in partial fulfillment of the requirements for the degree of Master of Engineering.

\begin{tabular}{|r|r|}
\hline & $\begin{array}{r}\text { Supervisor } \\
\text { Department of Civil Engineering }\end{array}$ \\
\hline & Department of Civil Engineering \\
\hline & Date \\
\hline
\end{tabular}




\author{
ABSTRACT \\ Groundwater Protection Model at Niagara Using GIS Tools \\ Master of Engineering, 2006 \\ By Mafruha Ahmed \\ Department of Civil Engineering \\ Ryerson University
}

Groundwater is the safest and most reliable source of available freshwater. Although traditionally groundwater has been assumed to be free from contamination, numerous discoveries in recent years of toxic chemicals in well water have proven this assumption to be false. Groundwater contamination from chemical dump sites tends to attract the greatest public attention, but contamination from other sources such as septic systems, pesticides, and underground storage tanks also can be significant. Intensive agriculture in areas of high soil permeability and high water tables also causes groundwater contamination from the percolation of chemicals and nutrients through the soil profile.

Protecting groundwater resources from pollution is therefore essential for its proper management and preventing probable hazards. Groundwater vulnerability assessment is an issue of spatial distribution and therefore typically carried out using geographic information systems (GIS). Even when using a simple qualitative method, the complex processing of spatial information is completed faster using GIS Models are tools to simulate the behavior of physical systems. They can predict the future evolution of the systems, they can be used as interpretative tools in order to study system dynamics and they can give hints for data collection and design of experiments. Models are sometimes used to examine the evolution of generic natural systems, without a specific application to a definite site or population. ArcGIS 9 provides new tools to build protection model to study groundwater contamination issues of various watersheds that performs multiple geoprocessing operations. The study articulates the most vulnerable locations of Niagara for ground water contamination, what geospatial data are needed to support these resource assessment activities, and how GIS tools are required to facilitate the generation of a best optimized model. 


\section{ACKNOWLEDGEMENTS}

I would like to express my deep gratitude to my supervisor, Prof. Songnian $\mathrm{Li}$ from the Department of Civil Engineering, Ryerson University for his attentive and comprehensive supervision, without which the completion of this study would have been difficult.

My special thanks go to Dr. James Li, Dr. Jonathan Li and Dr. Mostafa Warith as their courses are good resources for me. I also want to emphasise valuable assistance of the Ryerson staff for providing me with their help during the academic years.

Many thanks to my friends, specially Mahbuba and Iqbal for their enormous support, which encouraged me to the completion of this study. 


\section{DEDICATION}

To my father in law 


\section{TABLE OF CONTENTS}

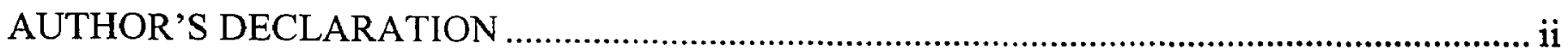

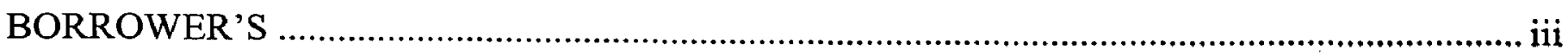

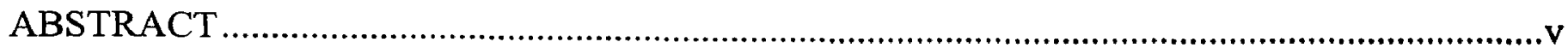

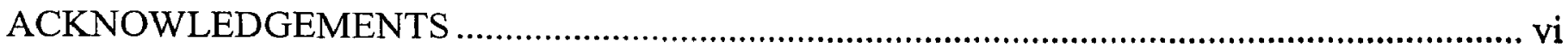

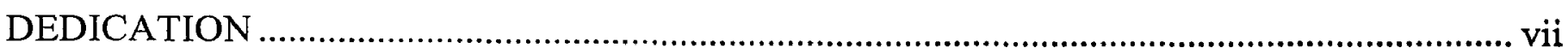

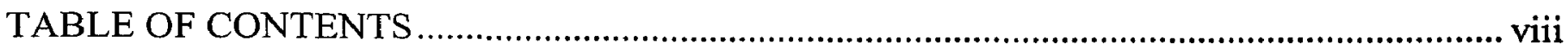

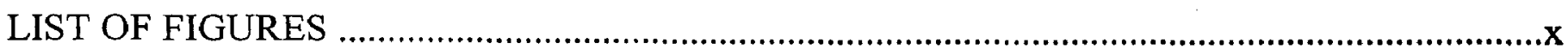

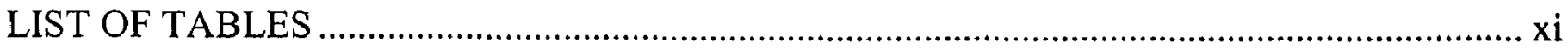

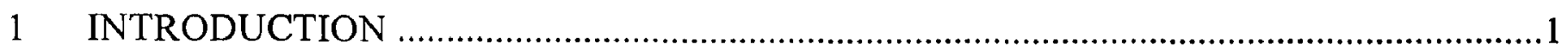

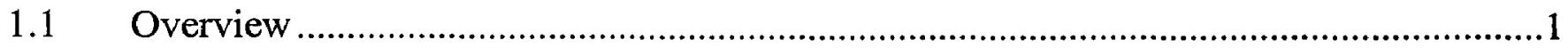

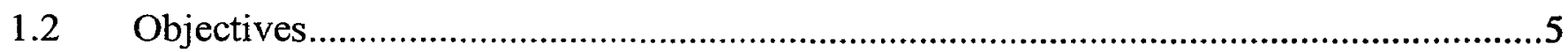

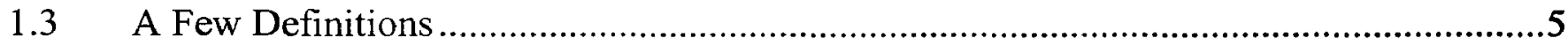

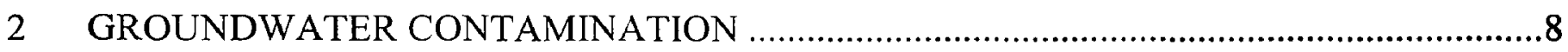

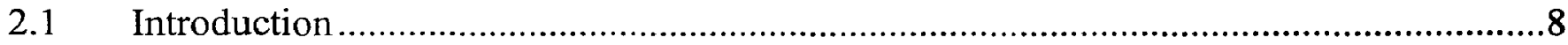

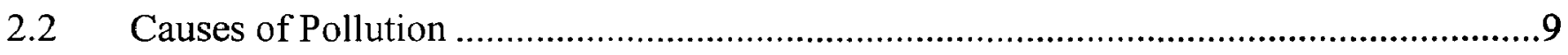

2.3 The Hydrologic Cycle ...........................................................................................10

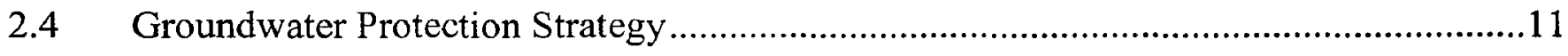

2.5 Groundwater Protection Strategy Approach ...............................................................15

2.6 Groundwater at the Region of Niagara ...................................................................

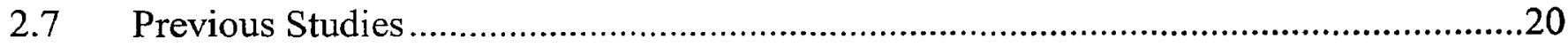

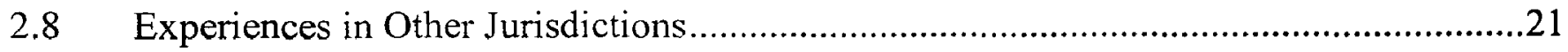

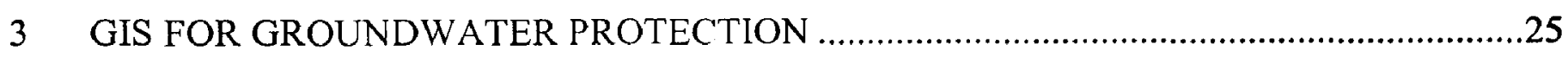

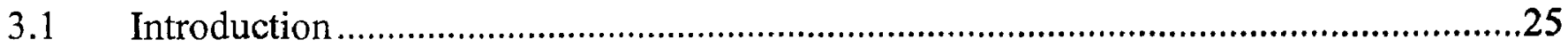

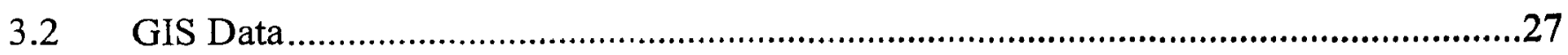

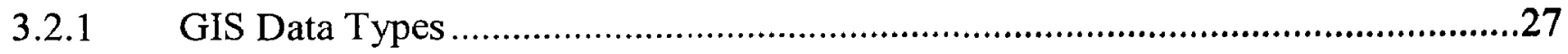

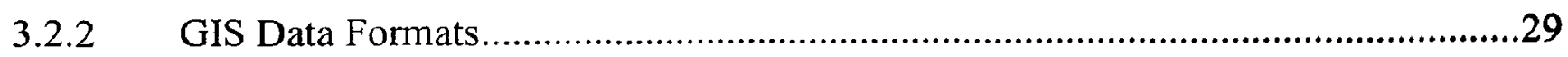

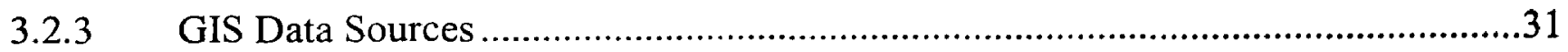

3.2.4 GIS Data Conversion and Integration ................................................................

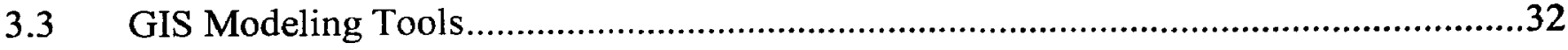




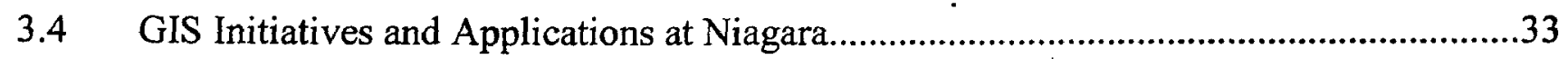

4 GROUNDWATER PROTECTION MODEL USING GIS TOOLS .......................................38

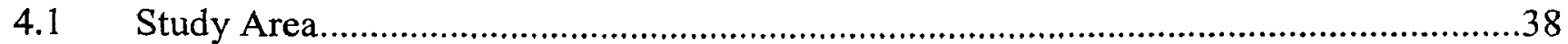

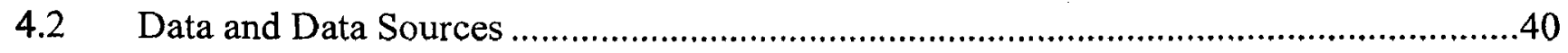

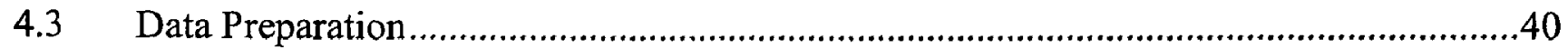

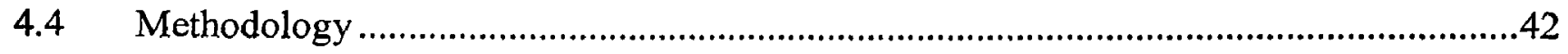

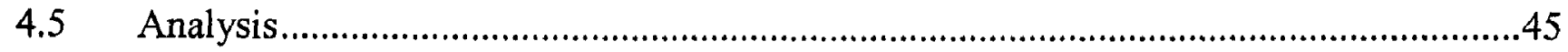

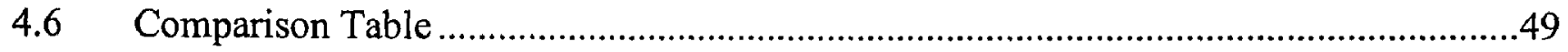

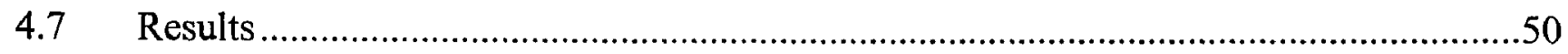

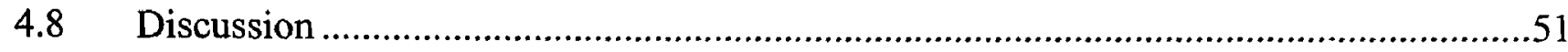

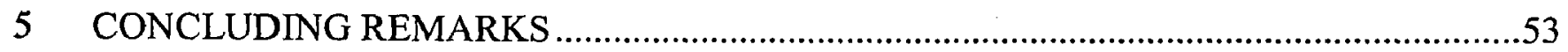

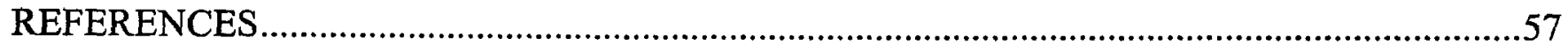




\section{LIST OF FIGURES}

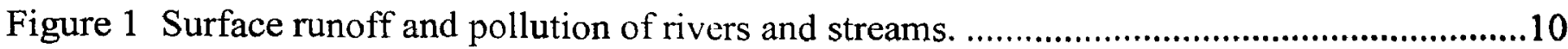

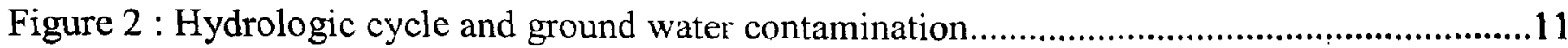

Figure 3 A multi-barrier approaches to water protection..............................................................

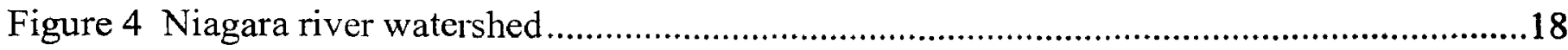

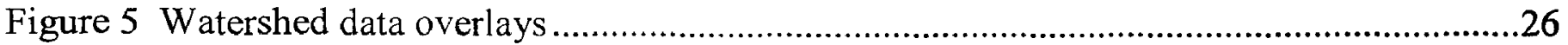

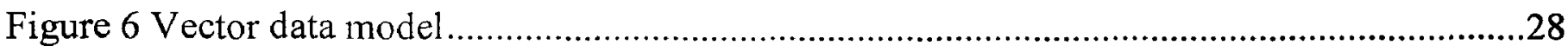

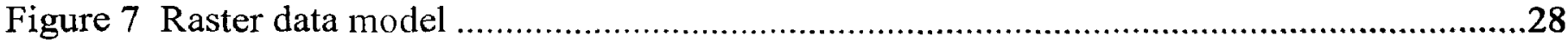

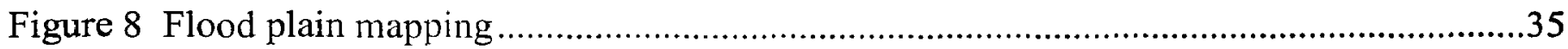

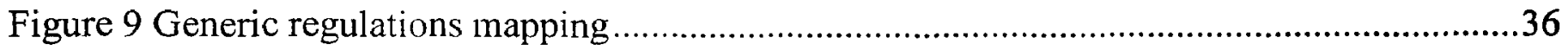

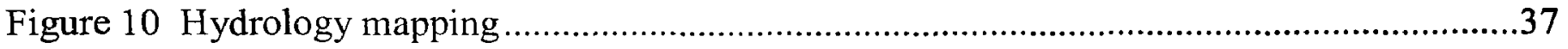

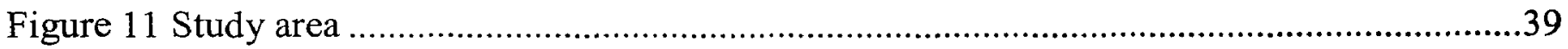

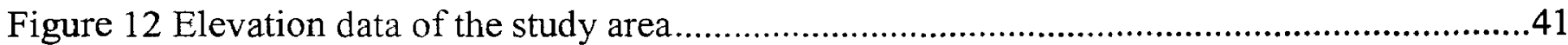

Figure 13 Personal geodatabase feature class - Niagara.mdb .....................................................42

Figure 14 Natural and landuse layer of study area.........................................................................43

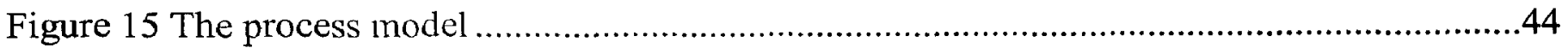

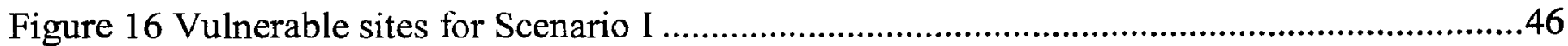

Figure 17 Vulnerable sites for Scenario II .............................................................................47

Figure 18 Vulnerable sites for Scenario III ............................................................................48

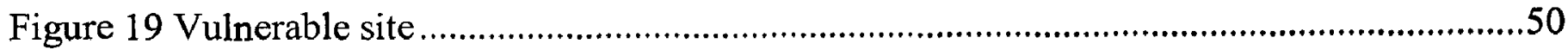




\section{INTRODUCTION}

\subsection{Overview}

Groundwater is water that is found underground in the cracks and spaces in soil, sand, and rock. Groundwater is the safest and most reliable source of available freshwater. Only three percent of the Earth's freshwater are located in streams, lakes, and reservoirs. The remaining 97 percent of freshwater is obtained from underground (Environment Canada, 2006). Groundwater plays an important role in the hydrological cycle. Groundwater is essential to the viability of the environment, health and growth of a country's economy, particularly the agricultural sector and has important economic significance to a range of urban activities. Groundwater is the main source of drinking water to most of the people in rural areas.

There are two sources of water supply available to society - surface sources, which include rivers, lakes and reservoirs, and ground sources, which include wells and springs that tap aquifers and other underground sources. Over 8 million Canadians rely on groundwater as their source of drinking water (Environment Canada, 2006). Nowadays, the assurance of sufficient and safe water is a major concern in Canada and around the world. There is also concern that where certain bacterial or nitrate concentrations exceed drinking water guidelines in surface or groundwater, there may be negative health effects. Other sources of contaminations are, for example, spillage of fertilizers and pesticides during handling, runoff from the loading and washing of pesticide sprayers or other application equipment, using chemicals uphill from or within a few hundred feet of a well. Contamination of groundwater resource may therefore cause severe environmental and health hazards. As the flow of groundwater is very slow and subject to little turbulence, contaminants in groundwater does not dilute easily. Consequently, once the aquifers are contaminated they become very difficult and costly to remedy and in most cases are abandoned. Protecting groundwater resources from pollution is therefore essential for its proper management and preventing probable hazards.

Most human-caused groundwater contamination results from the interaction of recharge water with chemicals at or just below the land surface. The concept of utmost importance is that groundwater originates at the Earth's surface, so its quality is determined by land uses and 
chemical management practices. As water percolates through the soil, it may pick up contaminants and carry them downward to groundwater.

Chemicals may be deliberately placed in or on the soil for a specific reason; for example, pesticides are sprayed to protect crops, and gasoline is stored in underground tanks for later use. Waste chemicals may be inadvertently spilled or deliberately applied to land for disposal. Soluble chemicals, which readily dissolve in water, move with groundwater as it flows. Insoluble chemicals do not mix fully with groundwater, and their flow patterns depend on their densities relative to water. The rates of movement and degradation of the compounds depend on a variety of chemical, physical, and biological processes.

Niagara watershed covers approximately $2424 \mathrm{sq} . \mathrm{km}$. covering the whole Niagara Region, $21 \%$ of the City of Hamilton and $24 \%$ of Haldimand County (Regional Municipality of Niagara, 2003). The watershed is drained primarily by the Welland River, Twelve Mile Creek, Twenty Mile Creek, and Forty Mile Creek with a number of smaller water courses draining into Lake Ontario and Lake Erie. The NPCA (Niagara Peninsula Conservation Authority) jurisdiction also encompasses $117 \mathrm{~km}$. of Great Lakes shoreline, with $67 \mathrm{~km}$. on Lake Erie and $50 \mathrm{~km}$. on Lake Ontario (Regional Municipality of Niagara, 2003). The watershed also includes many small tributaries draining directly to the Niagara River from the Town of Grand Island, New York, upstream of Niagara Falls. Waters from the Niagara River are withdrawn for hydroelectric power generation in both the U.S. and Canada and returned to the Niagara River below Niagara Falls. The Niagara River is the outlet for Lake Erie and the rest of the Great Lakes Basin upstream of Lake Ontario. Eighty-three percent $(83 \%)$ of the water flowing into Lake Ontario enters through the Niagara River and therefore significantly influences Lake Ontario's water quality and fish productivity. The Niagara River is now one of the U.S.-Canadian International Joint Commissions 42 "Areas of Concern" throughout the Great Lakes Basin (Regional Municipality of Niagara, 2003).

Close proximity to Lakes Erie and Ontario impacts rainfall and snow patterns, moderating the climate of the Region of Niagara allowing for production of a diverse variety of crops. There are 2266 farms and 205,348 acres of farmland within the watershed (Regional Municipality of Niagara, 2003). Important agricultural sectors include dairy, vegetable production, nursery stock, sod, greenhouse horticulture, vineyards, and small fruit production. Resource concerns revolve 
around water quality as well as erosion and sediment control, particular as it relates to flooding prevention, storm water runoff and resuspension of contaminated sediments. Most point sources, including industrial discharges, leaking landfills and municipal sewage discharges are reasonably well controlled but non-point sources of pollution particularly agricultural chemicals remain of concern and nutrient, manure, and pest management are particularly important agricultural conservation practices in this watershed.

The Niagara is recognized as one of the most significant agricultural areas in Canada. The agricultural contamination sources vary and there are numerous in this area. Agricultural inputs such as fertilizer, livestock manure, and pesticides have still caused water contamination when improperly stored, applied or disposed of high concentrations of organic matter, phosphorus and nitrogen in surface water can lead to its eutrophication and deoxygenation, which in turn destroy aquatic habitat and produce taste, odor and aesthetic problems. Through a combination of climate, soils, geography, and location, the area has developed an agricultural industry and community that is unique in Canada. Its positioning between two of the largest fresh water lakes in the world gives it a natural advantage for agriculture not only because of the moderating influence of the lakes, but also the ready availability of fresh water. Large quantities of organic compounds are used by agriculture. These man-made organic compounds are of most concern for groundwater contamination too.

The Niagara rely heavily on groundwater as a source of supply for its drinking water needs, and are fortunate that the quantity of groundwater available is capable of meeting the current water demand and that the water is of excellent quality. However, potential threats to the quantity and quality of this resource exist within the area. The basic groundwater functions (recharging, transmitting, assimilating potential contaminants, storing and discharging water) play an essential role in maintaining the health of an ecosystem. Better understanding of these regional groundwater functions is helpful to provide a secure supply of clean water to municipal and communal water systems, as well as to individual groundwater users who do not have access to a municipal supply.

There are currently 7400 wells in this region, among them only 150 wells are used (Regional Municipality of Niagara, 2003). Theoretically, there is unused capacity within the regional aquifers as the current use is only $15 \%$ of the recharge at the regional level (Regional Municipality of Niagara, 2003). The attempts to use groundwater from below the escarpment have often failed 
due to the high sulfur content of the extracted water. There are $4898 \mathrm{~km}$ of streams in Niagara Regions, averaging $2.02 \mathrm{~km}$ of drainage channel per square kilometer (Regional Municipality of Niagara, 2003). The average annual urban and rural storm runoffs are 56 million cubic meters and 27 million cubic meters, respectively (Regional Municipality of Niagara, 2003). Unfortunately most of the runoff occurs during periods of rain and this runoff from steep-sloped agricultural fields is one likely source of groundwater contamination. Based on these considerations, agricultural fields near streams should be identified and protection measures of groundwater contamination should be applied.

As groundwater is the only source of potable water in this region, assessing the health risks from chemicals and protecting humans are given high priority in governmental decisions. To this end a complex procedure is required that integrates research and technical expertise from various scientific disciplines. The fate of contaminants in the soil and groundwater as affected by a variety of environmental and anthropogenic processes and factors would certainly be included in the study. The evolution of existing, and the development of new, agricultural practices and other measures of groundwater quality control and management also be considered.

Groundwater recharge is the portion of infiltrating water that will move downward through the unsaturated zone. When infiltration reaches the water table it becomes groundwater recharge. Recharge replenishes water in aquifers, or is discharged in springs, streams, lakes, or wetlands. Whether well water is taken from individual wells or large community well fields, the concepts behind its protection remain the same.

Model can predict the future evolution of the systems, it can be used as interpretative tools in order to study system dynamics and they can give hints for data collection and design of experiments. Models are sometimes used to examine the evolution of generic natural systems, without a specific application to a definite site or population. More generally, models help to unlock latent tendencies in data, test our understanding of system structure and dynamics, and discuss policy issues in ways that expose assumptions and rules of inference. In ArcGIS, a model is a representation of a system of processes that performs operations on GIS datasets. Through the visual model-building interface, proposed analyses are more easily translated into ordered steps. Models allow data and tools to be linked together in a user-defined sequence that structures automated geoprocessing tasks such as buffering, converting, overlaying or selecting data. By the 
groundwater protection modeling the steep-sloped agricultural areas in this region can be identified which is susceptible to contaminate the groundwater through precipitation and which is discharged in springs, streams, lakes, or wetlands.

\subsection{Objectives}

The Niagara watershed characterized by caves, sinkholes, rapid groundwater flow, and many surface streams which are vulnerable to contamination, and groundwater quality in these areas are often closely related to land use practices. The runoff from the steep-sloped agricultural lands is discharged to nearby streams which ultimately discharge to Lake Erie and Lake Ontario. These areas are likely to posses a greater influence on the watershed's groundwater quality by infiltration of runoff. The objective of this report is to build a groundwater protection model of Niagara by performing multiple geoprocessing operations using the model builder module of ArcGIS version 9. The intention of the protection model is to define the areas where the run-off from the steepsloped crop fields is one likely source of groundwater contamination by agricultural chemicals. Areas defined through the model are most vulnerable to contamination of groundwater as the runoff infiltrates through different soils and possibly recharge an aquifer or contributes water to a pathway delivering water to an aquifer.

\subsection{A Few Definitions}

Recharge - Water percolates through the soil to become groundwater in a process called recharge. The amount of water recharged in any particular location depends on a number of factors, including climate, land use, topography, and geological conditions.

Groundwater - Groundwater moves through the ground, below the place where it first enters the soil to the area where it later resurfaces. Flow rates typically are measured in inches or feet per day, although they can be much faster in coarse gravel or in bedrock with large openings or crevices. Groundwater tends to move in parallel paths, with little vertical mixing between layers. Geological formations that yield significant amounts of groundwater are called aquifers.

Aquifers - A geological formation capable of storing and yielding significant quantities of water. It is usually composed of sand, gravel, or permeable rock which lies upon a layer of clay or other impermeable material. This impermeable layer does not allow the water to penetrate to lower depths. Thus, various aquifers can be present at various depths. The low permeability formation 
located above and/or below an aquifer is called an aquiclude. Aquifers can be divided into two basic types. Unconfined aquifers have an upper water surface that is free to rise and fall depending on the volume of groundwater present. The groundwater surface in an unconfined aquifer is called the water table. The level of water in a well tapping an unconfined aquifer is the same as that of the surrounding water table. Confined or artesian aquifers contain groundwater that is trapped under a layer of impermeable material such as clay. Hydraulic pressure causes water in an artesian well to rise above the top of the aquifer. Some aquifers consist of porous media such as sand and gravel. Others occur where groundwater fills cracks and openings in bedrock or where groundwater has dissolved caverns in limestone or gypsum bedrock. These aquifers may have high rates of flow and little filtering of contaminants compared with aquifers in porous media.

Contamination - The definition of contamination is defined as the presence of foreign materials, chemicals or radioactive substances in the environment (soil, sediment, water or air) in significant concentrations. Introduction into water, air, and soil of microorganisms, chemicals, toxic substances, wastes, or wastewater in a concentration that makes the medium unfit for its next intended use. Also applies to surfaces of objects, buildings, and various household and agricultural use products.

Watershed - Watershed defines any area lying within the drainage basin of any reservoir.

Karsts - An area of irregular limestone in which erosion has produced fissures, sinkholes, underground streams, and caverns.

Cone of depression - Groundwater movement is affected by the pumping of wells. When water is withdrawn from a well, the water table around the well is lowered, and groundwater from surrounding areas flows toward the well to compensate. The lowered water table around a well is called the cone of depression. The size and shape of the cone of depression depend on many factors, including the rate and duration of pumping, the rate of groundwater recharge, and the geology of the aquifer.

Zone of influence - The area at the land surface lying directly over the cone of depression is called the zone of influence. Although the zone of influence indicates the area in which the water table elevation is affected by a well, it does not necessarily coincide with the land area contributing recharge water to the well. This area, called the zone of contribution, usually is larger 
than the zone of influence. It may include parts of the zone of influence or extend miles from the well location, depending on the type of aquifer being tapped.

Parameter - A variable, measurable property whose value is a determinant of the characteristics of a system; e.g., temperature, pressure, and density are parameters of the atmosphere. Or, a measurable or derived variable represented by the data (e.g. air temperature, snow depth, relative humidity (Source: [SPSO, 2001]).

Conceptual model - A depiction or representation of the most current understanding of the major ecosystem features and processes (including biological, physical, chemical, and geomorphic components) of a particular environment (e.g., estuaries).

Vulnerability - Vulnerability is a term used to represent the intrinsic geological and hydrogeological characteristics that determine the ease with which groundwater may be contaminated by human activities.

\subsection{Structure of report}

This report consists of five chapters including an introduction and conclusion. Following the introduction the second chapter provides a brief description about the groundwater contamination and causes, and discusses all the issues of ground water protection strategy that have been taken into account to avoid or minimize impacts. Third chapter narrows down to GIS applications of Groundwater, GIS data types, and some GIS initiatives and application at Niagara Region. Fourth chapter presents datasets and the methodology used to develop groundwater protection model using GIS tools at Niagara. Finally, concluding remarks are presented in the fifth chapter. 


\section{GROUNDWATER CONTAMINATION}

\subsection{Introduction}

Pure water is tasteless and odorless. A molecule of water contains only hydrogen and oxygen atoms. Water is never found in a pure state in nature. Both groundwater and surface water may contain many constituents, including microorganisms, gases, inorganic, and organic materials. Scientists assess water quality by measuring the amounts of the various constituents contained in the water. There are many different types of potential threats to groundwater quality, which may include organic chemicals, hydrocarbons (e.g., benzene in gasoline and TCE in solvents), inorganic cations (e.g., iron and manganese), inorganic anions (chloride and nitrate), pathogens (bacteria and viruses), and radio nuclides (radon and strontium) (Fetter, 1999).

Any addition of undesirable substances to groundwater caused by human activities is considered to be contamination. Groundwater contamination may occur from either point sources or nonpoint sources of contamination. These terms generally describe the localization of the contaminant. A point source is typically a small-scale contaminant source area, such as a leaky underground fuel storage tank, or a landfill. Non-point sources, in contrast, are larger in scale and are typically more diffuse than point source contaminants. Non-point sources are primarily related to land use practices (fertilizer spreading, road salting), whereas point sources may be related to localized contamination events (contaminant leaks or spills).

Contamination problems are increasing in Canada primarily because of the large and growing number of toxic compounds used in industry and agriculture. In rural Canada, scientists suspect that many household wells are contaminated by substances from such common sources as septic systems, underground tanks, used motor oil, road salt, fertilizer, pesticides, and livestock wastes. Scientists also predict that in the next few decades more contaminated aquifers will be discovered, new contaminants will be identified, and more contaminated groundwater will be discharged into wetlands, streams and lakes.

"The Ontario Drinking Water" standards were designed to protect public health through the provision of safe drinking water (MOE, 2001). Water intended for domestic use should not contain disease-causing organisms, or unsafe concentrations of toxic chemicals or radioactive 
substances. Water should be aesthetically acceptable, and parameters such as taste, odor, turbidity, and color should be controlled. Drinking water quality criteria must take into consideration several factors that may impact the quality of drinking water, public health, and technology available to treat the water. Both 'standards' and 'objectives' are outlined in the 'Ontario Drinking Water Standards'. If a parameter is assigned a 'standard' there is a maximum acceptable concentration (MAC) assigned to the parameter. The MAC is a health-related standard established for parameters which, when present above a certain concentration, are known or suspected to cause adverse health effects.

In the Region of Niagara the principal source of contamination is agriculture and particularly the intensive application of nitrogen and phosphorus fertilizers. Besides this livestock manure and pesticides are also responsible for groundwater contamination of this region. On the other hand currently only 150 wells are used among 7400 wells in this region due to the high sulfur content of the extracted water (Regional Municipality of Niagara, 2003). In the Region of Niagara, pollution of surface water by groundwater is probably at least as serious as the contamination of groundwater supplies. Preventing this non-point source contamination in the first place is by far the most practical solution to the problem.

\subsection{Causes of Pollution}

The pollution of water with chemical contaminants has become one of the most crutial environmental problems within the 20th century. Pollution is also caused when silt and other suspended solids, such as soil, washoff plowed fields, construction and logging sites, urban areas, and eroded river banks when it rains. Figure 1 shows the pollution of river and stream of a watershed due to surface runoff. Pollution in the form of organic material enters waterways in many different forms as sewage, as leaves and grass clippings, or as runoff from livestock feedlots and pastures. When natural bacteria and protozoan in the water break down this organic material, they begin to use up the oxygen dissolved in the water. Many types of fish and bottom-dwelling animals cannot survive when levels of dissolved oxygen drop below two to five parts per million. When this occurs, it kills aquatic organisms in large numbers which leads to disruptions in the food chain. 


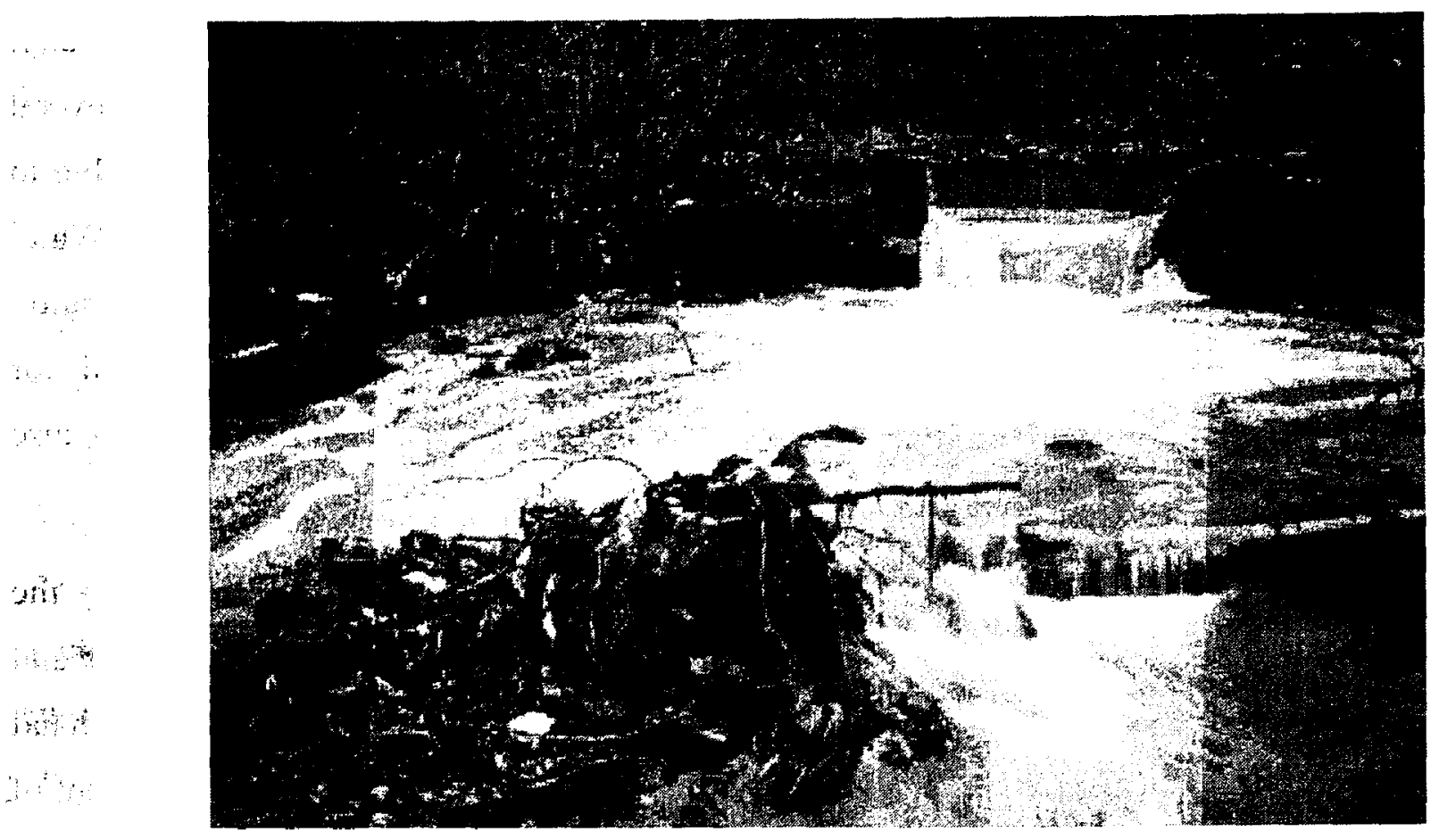

Figure 1 Surface runoff and pollution of rivers and streams.

(Source: [David, K., 2000, Water Pollution and Society])

\subsection{The Hydrologic Cycle}

The movement and recycling of water between the atmospheres, land surface, and underground is called the hydrologic cycle. Understanding the hydrologic cycle, and in turn the flux of water moving into and out of a study area, is critical in properly managing water resources. The hydrologic cycle consists of four main components: precipitation, evapotranspiration, surface water resources, and groundwater resources.

Water on the ground surface, in streams or in lakes can return to the atmosphere through evaporation. Water used by plants can be returned to the atmosphere through transpiration (see Figure 2). Groundwater is vulnerable to contamination from a variety of sources. These contamination problems stem partly from land-based development and mainly from agricultural sector. 


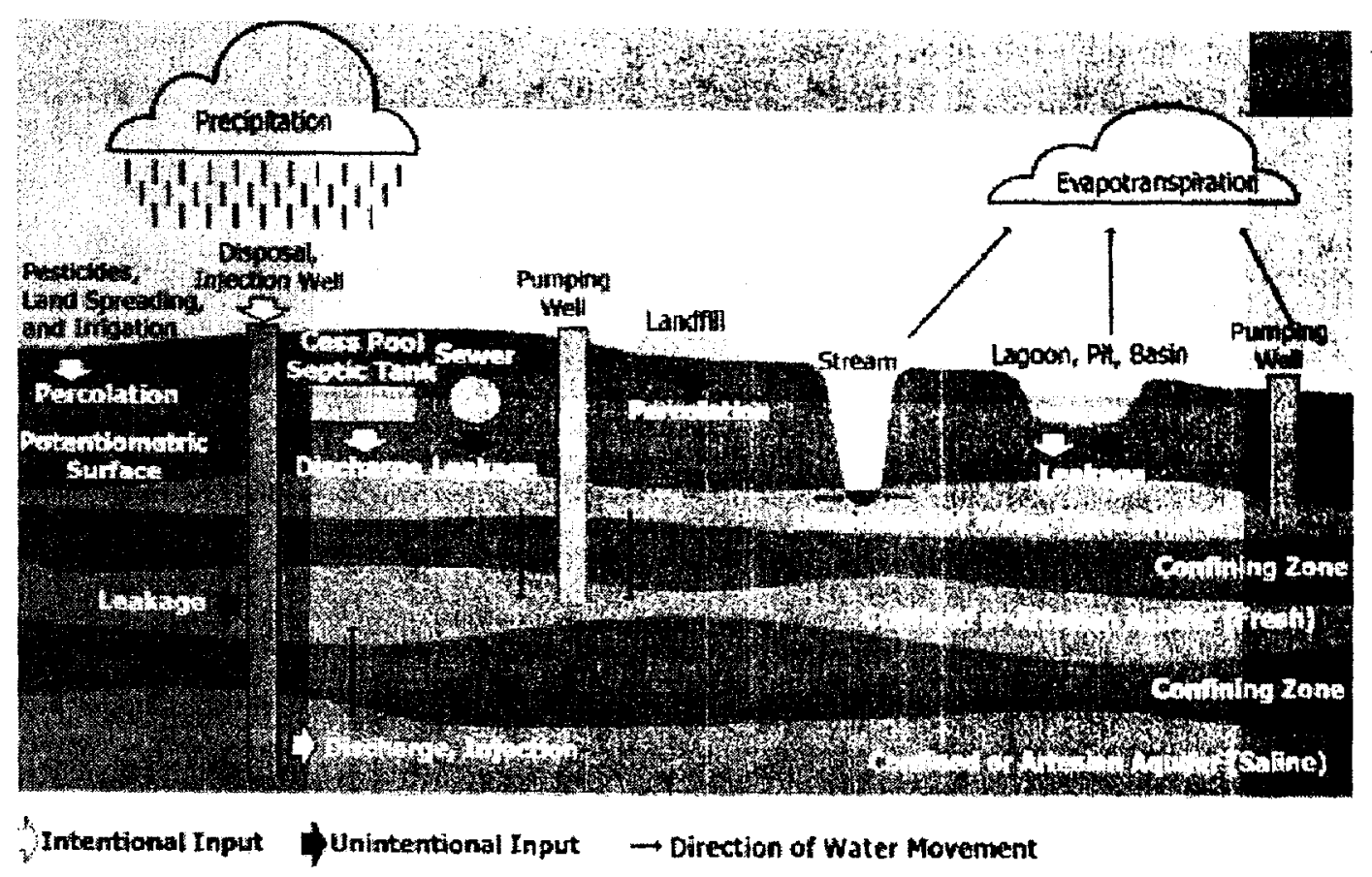

Figure $2:$ Hydrologic cycle and ground water contamination

(Source: [Environmental Protection Agency, 1977])

\subsection{Groundwater Protection Strategy}

A Groundwater Protection Strategy is a program of risk reduction to sustain the groundwater resource, both as a source of drinking water supplies and as an integral component of the ecosystem. The strategy can incorporate a number of different tools, which may include a combination of land use policies, regulatory controls, best management practices, public education, groundwater monitoring, land acquisition, conservation easements, and spills contingency planning.

Best management practices may apply to a homeowner in the use and storage of solvents, pesticides, and the disposal of household hazardous wastes. For the agricultural industry it may include measures such as stream buffering from cattle grazing and the care with which manure and other fertilizers are applied.

It is recommended that Niagara Region, in consultation with the MOE (Ministry of Environment), develops and implements a Groundwater Protection Strategy that incorporates some of the different components. The importance of groundwater to Niagara Region underscores the need to manage the resources. The Groundwater Protection Strategy should be developed to address the following components: 
- Ensure that the data is properly managed,

- Use public education to foster groundwater protection,

- Acknowledge and protect Wellhead Protection Areas,

- Acknowledge and protect areas of medium and high vulnerability,

- Monitor groundwater quality, and

- Encourage the use of Best Management Practices.

Resource endeavors geared towards providing a safe and secure water source for the Region. Discussion related to the multi-barrier approach to water protection is included to provide this link. The multi-barrier approach is an integrated system of procedures, processes and tools that collectively prevent or reduce the contamination of drinking water from source to tap, in order to reduce risks to public health (Canadian Council of Ministers of the Environment, 2002). Figure 3 illustrates the multi-barrier approach schematically, highlighting three key processes of source protection, treatment, and distribution.

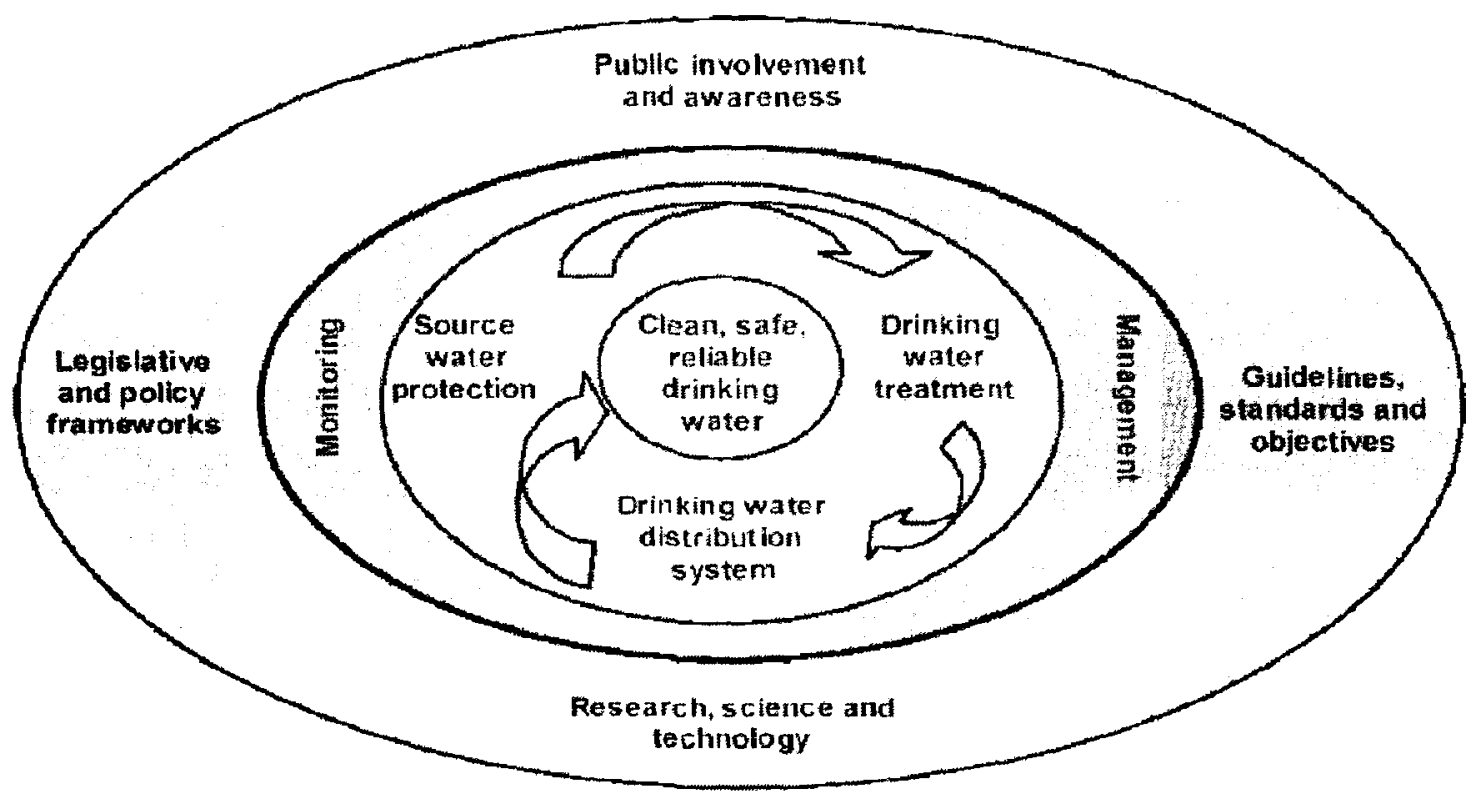

Figure 3 A multi-barrier approaches to water protection.

(Source: [CCME, 2002])

Source protection is the first of five barriers commonly applied to provide safe drinking water (O'Connor, 2002). The other four barriers include treatment, a secure distribution system, water quality monitoring, and well-planned responses to adverse conditions. These potential impacts of agricultural activities on the natural environmental include contamination from excessive 
nutrients, pathogens, sediment, pesticides, and organic materials. These contaminants could potentially affect the color, smell and taste of water, and can be represented by four distinct components:

- Extent of agriculture within an area, which is represented by the fraction of agricultural land within the total area.

- Nature of agricultural activity - There are two major interrelated biological systems involved in agricultural production activities: those related to crop production and those related to livestock production.

- Intensity of the agricultural activities as indicated by the levels of management (livestock type and quantity, tillage, nutrient amendments, and pesticides) compared to levels normally used in agricultural enterprises.

- Proximity is an indication of the connection pathway between agricultural activities and the component of the agro-ecosystem resource under consideration. For example, crop production on tile drained land or adjacent to streams or drainage ditches is more likely to result in contamination of surface water than on land that is farther from surface drainage.

Utilizing best management practices (BMPs) can greatly reduce the risk that different actions have on groundwater resources. Providing information about BMPs in sensitive areas such as WHPAs (wellhead protection areas) can help to protect groundwater resources.

Land Acquisition Acquiring land in a highly sensitive area should provide complete control over the land use practices within the area. In many cases this option is not feasible due to costs and other factors. Land can be acquired prior to the development of a new water supply, or future water supplies can be developed in areas where land is owned by the municipality.

Conservation Easements A conservation easement is a voluntary agreement between a landowner and a conservation body to "conserve, maintain, restore or enhance" the natural features of a property by placing conditions on its management. The easement is a legal document that is registered on the title of the property, and binds the present owner and all future owners to the terms of the agreement. A conservation easement does not give the easement holder title to the property. For landowners, a conservation easement is a way to protect the special attributes of their property by placing a permanent development restriction on the property, while retaining 
ownership. This tool has been available since 1995, when the Conservation Lands Act was revised to allow private landowners to enter into conservation easement with charitable conservation organization, municipal councils, native bands, and conservation authorities. Prior to this, landowners could only enter into conservation easements with the Crown and its agencies.

Incentive Programs Incentive programs can be used to encourage specific actions throughout the Region or within specific sensitive areas such as WHPAs. A variety of incentive programs currently exist, such as those administered by the Ontario Ministry of Agriculture and Food (Healthy Futures). Additional incentives, focused in higher risk areas, can be used to properly decommission abandoned boreholes, upgrade existing chemical storage, properly maintain septic systems, compensate for loss of land use or productivity, and provide hazardous waste disposal.

Municipal Site Leadership By adopting an active role and implementing BMPs at municipal sites, the Region and their member municipalities will have much more credibility when asking other land users to adopt similar policies. In many instances, public lands reside in the most sensitive areas from WHPA perspectives. An audit of each well house and the area around the well, and the subsequent removal of potential contaminant sources such as fertilizers, lawn chemicals, paints, oils, fuels, and other contaminants can be completed.

Integrated Information Management An information management system is essential to incorporate all available information during decision-making. A relational database linked to a GIS can bring together water quality, WHPAs, groundwater vulnerability, land uses, potential and known contaminant sources. Information can also be implemented in a web application for distribution to county residents.

Water Quality Monitoring The development of "sentinel wells" to provide water quality monitoring that could detect adverse water quality conditions up gradient of the production wells provides a warning system of potential well contamination. Sentinel wells are typically located a distance, in groundwater time-of-travel, of 2 to 5 years up gradient of the production well to provide opportunity to investigate and mitigate water quality concerns. Threshold levels, with associated action plans are important facets of this groundwater management tool.

Municipal Sewer By-Law A sewer by-law provides a means to control the substances that are discharged to the sewer. Sewers can leak and be a source of contamination to groundwater. Furthermore, as part of the by-law, inspections could be carried out to help ensure suitable 
chemical storage. An inventory of chemical storage provides additional information that can be used to promote BMPs.

Official Plan Amendments Official Plan amendments can address specific land uses and can define different sensitive groundwater zones. These zones can include WHPAs and areas of high intrinsic susceptibility. Restrictions, or the requirement of site-specific information prior to the approval of specific land uses, provide a direct means of controlling land uses in sensitive areas.

Spill Contingency Plan A spill contingency plan promotes quick and deliberate responses to contaminant spills. A spill contingency plan typically includes information about specific responsibilities of individuals and organizations and contact numbers needed in the event of a spill.

\subsection{Groundwater Protection Strategy Approach}

A comprehensive approach to water resource management is needed to address the myriad water quality problems that exist today from non-point and point sources as well as from habitat degradation. The groundwater protection strategy approach is a management approach for more effectively protecting and restoring aquatic ecosystems and protecting human health.

The strategy can incorporate a number of different tools. These tools may include a combination of land use policies, regulatory controls, best management practices, public education, monitoring, land acquisition, and spills contingency planning. Policies, such as those in a municipal official plan, serve to identify the public interest in water quality and quantity. An official plan may establish goals, set objectives for water protection (aquifer and well head protection), and provide the framework for land use development and implementation measures. The policies may also provide the rationale for the use of other planning tools such as zoning and site plan control. These are regulatory mechanisms that may be used to control development on a lot-by-lot basis, or an area-wide basis. Planning applications, such as development or land use changes, largely drive the implementation process. Many tools are not retroactive and they do not enable a municipality to rectify a pollution problem by closing down an operation or forcing the relocation of an existing land use that may have the potential to contaminate an aquifer.

Best management practices are as the use and storage of solvents, pesticides, and the disposal of household hazardous wastes may apply to a homeowner. For the agricultural industry it may 
include measures such as stream buffering from cattle grazing and the care with which manure and other fertilizers are applied. The municipality may also use other statutes to complement the land use controls under the planning act. The Nutrient Management Act (NMA, 2001), and the associated regulations, for example, set out the requirements for the preparation of nutrient management plans and the control of intensive livestock operations. The NMA requires all farm operations to have a nutrient management plan. This ensures that all nutrients on the farm (from livestock, biosolids, and legume fixation and chemical fertilizers) are used with the best possible efficiency for crop production. This program also deals with various proximity hazards by requiring setbacks in nutrient applications from the surface drainage network and wells. Raising public awareness, through public educational programs, can have a major impact on groundwater protection and may be more important than enforcement measures. It is through the voluntary actions and practices of people on a day-by-day basis that will help protect water resources (i.e., proper use, storage and disposal of fuels, solvents, and pesticides, regular water well maintenance, installation of water saving plumbing fixtures). Municipalities can work towards developing a "water ethic" in their communities. This means instilling a collective awareness, responsibility, and commitment to protect water on an ongoing basis.

The approach to developing a protection strategy is based on a number of assumptions:

- Water is the single most important resource for a healthy community and, as a result, a preventative or proactive approach is more appropriate than a reactive approach (i.e., prevent contamination as opposed to cleaning it up),

- Water is not confined by political boundaries,

- While the focus is on groundwater protection, the linkage to surface water resources (i.e., water cycle) necessitates a broad-based approach,

- Existing risks can be reduced through redevelopment or relocation of land uses that may threaten water quality,

- Water quantity (well yields) will remain constant,

- Impacts can be monitored through development decisions and the collection of data and that the strategy will be adjusted, where necessary, and 
- A source protection strategy is a risk management tool that will not provide an absolute solution, but rather, will minimize potential negative impacts over the short and long term.

The protection of water quality and quantity depends on the collective actions of individuals, private industry, government, and other agencies. Rural property owners are responsible for maintaining their own well and septic tanks. Municipalities are responsible for the provision and maintenance of safe drinking water supplies in urban areas, and for proper sewage collection and treatment. Conservation authorities play an important role in water conservation through watershed protection and management. Private industry is intrinsically responsible for best management practices in the utilization of water for the goods and services they provide. The farm industry in particular, has an interest in securing an adequate supply of water for livestock and crop watering.

\subsection{Groundwater at the Region of Niagara}

The Niagara Region is located in the southern part of Ontario (Canada) between Lake Ontario and Lake Erie. Given the presence of Niagara Falls, the Niagara Region is home to one of the most renowned stretches of water; the Niagara River. The existing irrigation practice in this region depends on the existing irrigation infrastructures and existing water sources.

Most farmers in the Niagara-on-the-Lake (NOTL) irrigate. The irrigation is also widely practiced in St. Catherine too. The source of irrigation water in NOTL is generally the municipal drain systems (Niagara-on-the-Lake-Irrigation Systems); however, a few larger operations near Lake Ontario and the Niagara River use these surface water bodies as their sources. The NOTL Municipal Irrigation System operates from early May to mid- September, providing irrigation water through municipal drains to some 8,000 acres of irrigated land (Ontario Ministry of Agriculture, 2005). The current maximum capacity is 15,000 USGPM $\left(82,000 \mathrm{~m}^{3} /\right.$ day or 800 acreinches/day), using the Welland canal (shown in map below), Niagara River and OPG (Ontario Power Generation Inc.) facilitates as sources. Besides this the new supply systems from the Niagara River includes a pumped intake on the Niagara River.

For other irrigation infrastructures, on-farm irrigation infrastructures used currently is also significant. Where accessible water sources exist, many farmers have on-farm capacity for applying sufficient amounts of water to most of their land. There is also substantial on-farm storage in these areas. Some of the irrigators in these areas have on-farm ponds for irrigation. A 
few farmers have raw water supply systems for irrigation, generally supplied by Lake Ontario or Niagara River and some times from drilled wells. The Welland canal (shown in Figure 3 ) that was constructed between Lake Erie and Lake Ontario is also as one of the sources of NOTL irrigation systems.

The existing natural water sources for irrigation are Lake Erie, Lake Ontario, Niagara River, surface streams and run-off (which is stored during rainy season), and groundwater. Lake Erie marks the southern border of the Niagara Region. Its water flows through and by the Region via a number of natural and man-made waterways. Niagara River is the western boundary (see Figure 4). The waters in downstream of the river have the advantage of being close to NOTL and supplied water for irrigation. Lake Ontario makes the northern boundary, which is relatively close to majority of the agricultural lands. The major advantage of this source is the seemingly unlimited capacity as a supply for irrigation water. The surface streams and runoff are also another good source of irrigation. For this most farmers have on-farm water storage ponds or cisterns which actually they used in dry seasons.

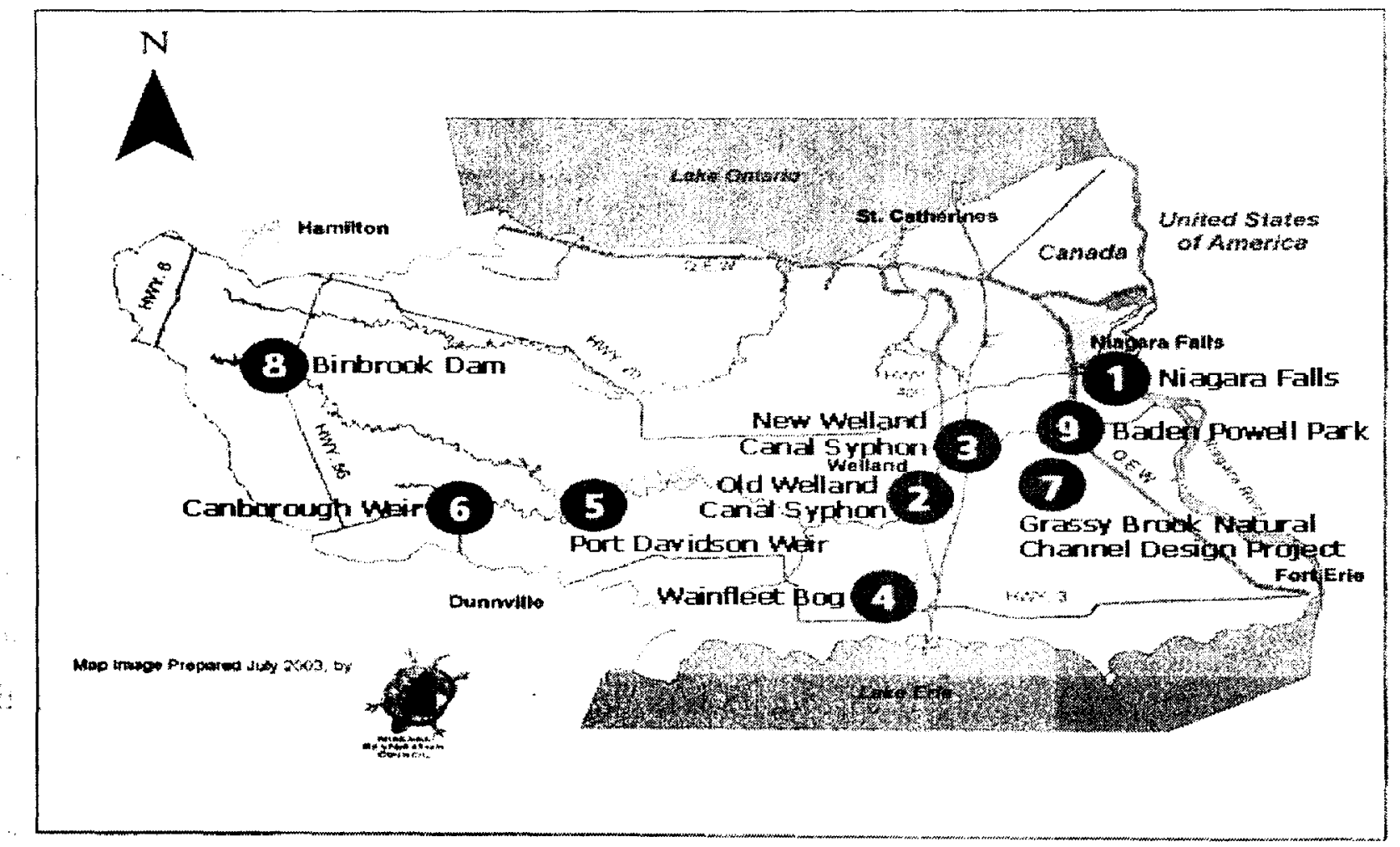

Figure 4 Niagara river watershed

(Source: [Niagara Restoration Council, 2003]) 
Irrigation is generally practiced in from early July to mid-September. Most farmers have invested their substantial capital on irrigation systems. However, even those who practice irrigation have some sites that are not irrigated due to source limitations or unfeasibility of irrigation. Even at sites that have irrigation, most farmers cannot get the option of connecting to a regional water supply system. Therefore a large part of farmers to meet their requirements use groundwater.

Groundwater is a significant source of rural, residential, and agricultural water supply within the jurisdictional area of the Niagara. Groundwater sustains most rivers, lakes, and wetlands in this region, especially during times of drought. The increasing demand for groundwater supplies to support crop irrigation, aggregate extraction, and urban development are potentially creating additional stresses on the availability of groundwater supplies at Niagara. Unfortunately theoretically, there is unused capacity within the regional aquifers as the current use is only $15 \%$ of the recharge at the regional level (Regional Municipality of Niagara, 2003). Therefore a variety of potential groundwater contamination risks have been identified, including, improperly constructed and/or abandoned water wells, fertilizers, pesticides, septic systems, road salt, landfill sites, and historic oil exploration. The land cover and land use in the Region of Niagara are shown in Table 1.

Table 1 Land cover and landuse (Source: [Environment Canada, 2001])

\begin{tabular}{|c|c|}
\hline Land Use & Totals \\
\hline Surface Areas & 514,810 acres \\
\hline Numbers of Farms & 2266 \\
\hline Numbers of Greenhouse & 231 \\
\hline Acers Farmed & 205,348 acres \\
\hline Cropland & 174,300 acres \\
\hline Pasture & 60,900 acres \\
\hline
\end{tabular}

For the purpose of estimating rural domestic ground water use it is assumed that the most of the rural population in Niagara uses private wells for domestic uses and the estimated domestic use is 175 1/person/day (MOE, 2001). Quantity of domestic ground water use and current rate of permitted withdrawal are shown in Table 2 and Table 3. 
Table 2 Domestic ground water use (Source: [Environment Canada, 2001])

\begin{tabular}{|c|c|c|}
\hline Name & Population & $\begin{array}{c}\text { Domestic ground water use } \\
\left(\mathbf{m}^{\mathbf{3}} / \mathbf{d a y}\right)\end{array}$ \\
\hline Region of Niagara & 51971 & 9095 \\
\hline
\end{tabular}

Table 3 Current rate of permitted withdrawal (Source: [Environment Canada, 2001])

\begin{tabular}{|c|c|c|c|}
\hline Name & Purpose & $\begin{array}{c}\text { Max withdrawal } \\
\mathbf{m}^{\mathbf{3}} / \mathbf{d a y}\end{array}$ & $\begin{array}{c}\text { Average } \\
\left(\mathbf{m}^{\mathbf{3}} / \mathbf{d a y}\right)\end{array}$ \\
\hline \multirow{2}{*}{ Niagara Falls } & Commercial & 1352 & 983 \\
\cline { 2 - 4 } & Industrial & 19548 & 2674 \\
\cline { 2 - 4 } & Agriculture & 3600 & 3600 \\
\cline { 2 - 4 } & Dewatering & 14402 & 14402 \\
\cline { 2 - 4 } & Industrial & 7845 & 7845 \\
\hline
\end{tabular}

Previous study indicated that the total estimated agricultural water use is $11479429 \mathrm{~m}^{3}$ per year and $31450 \mathrm{~m}^{3}$ per day. Water used for agricultural purpose is greatest during the growing season and that is $91257 \mathrm{~m}^{3}$ per day. Total Groundwater used for the area is about 56 million $\mathrm{m}^{3}$ per year. Ground water recharge is estimated as 222 million $\mathrm{m}^{3}$ per year. Used is $25 \%$ of recharge. Roughly $70 \%$ of land use at Niagara is agricultural land (Muller, 1994).

Data for the groundwater use assessment was obtained from various sources, such as the MOE Permit to Take Water (PTTW) database, MOE Water Well Information System (WWIS), and the MNR report "Agricultural Water Use in Ontario by Watershed: Estimates for 2001" (Rob, L., 2002).

\subsection{Previous Studies}

Numerous reports related to groundwater resources investigation and conservation in the Niagara has been published over the past few years. These reports include local-scale hydrogeologic analyses, as well as regional-scale assessments of groundwater resources within the region. They provide a useful source of information on the geology and hydrogeology of the region. 
As part of developing a water and wastewater servicing strategy for the Township of Waintleet. a Groundwater Impact Assessment was completed for the Regional Municipality of Niagara (MacViro, 2002). This study identified and assessed the potential impacts of the existing private water and sewage systems on the health and safety of the public and the environment along the Lake Erie shoreline near the Onondaga Escapement. Due to the presence of fractured bedrock and areas of thin soil cover, the study concluded that much of the study area would be defined as hydrogeologically sensitive. The report indicated that MOE would not normally support development on individual services in these locations (MacViro, 2002 and MOE, 1996). Local groundwater resources as a result were considered at high risk of contamination from bacteria, nitrate, and other sewage effluent contaminants.

A study was completed for the Niagara-Welland are to assess groundwater resources in the Niagara area to provide a framework for future studies and to quantity the impact of toxic chemical loading to the Niagara River (Lee, 1987). The study looked in detail at the geology and hydrogeology of the Niagara area as well as the Welland River drainage basin, and found that the most significant water resource problems exist in isolated areas related to dewatering, irrigation, and flooding. The study also reported that the poor groundwater quality in the area is related to slow groundwater movement through the overburden, which permits significant chemical dissolution of naturally occurring chemical parameters. Groundwater quality problems from contaminant sources were found to have localized impacts. The total recharge to the bedrock aquifer was estimated for the study area to be the equivalent of $4 \mathrm{~m}^{3} / \mathrm{sec}$, and the groundwater takings were estimated to be equivalent to $0.3 \mathrm{~m}^{3} / \mathrm{sec}$, leading the authors to conclude that there appears to be sufficient groundwater in the area to support continued development.

Feenstra (1981) completed a report examining the surficial quaternary geology as well as the bedrock geology and industrial mineral potential of the Niagara-Welland area. This report provides excellent discussion on the origin of the landforms and surficial features of the area. The report also includes discussion on the aggregate (bedrock and overburden) potential in the study area.

\subsection{Experiences in Other Jurisdictions}

Source protection is not new in Ontario or other jurisdictions across North America. Groundwater protection programs are becoming more common in communities across North America due to the 
increased impetus to provide and protect clean drinking water. Many municipalities that rely on groundwater are taking proactive measures to safeguard the quality of their water from past, present, and future land uses.

Oak Ridges Moraine (Ontario) The Regional Municipalities of Durham, Peel, and York, in coordination with the Province of Ontario, developed a conservation plan for the Oak Ridges Moraine that includes a management strategy for groundwater. The Oak Ridges Moraine Conservation Act (2001), and the associated Ontario regulation complement the strategy by restricting land uses in WHPAs and in areas of high aquifer vulnerability. The groundwater management strategy identified "data collection and management, data analysis and policy development and implementation" as three broad action areas. The regulation prohibits the storage of petroleum products, pesticides, inorganic fertilizers, road salt, hazardous or liquid industrial wastes, severely toxic contaminants (Source: [Ontario regulation 347, 2001]), animal manure in wellhead protection areas along with waste disposal sites, snow dumps, animal agriculture, and the storage of agricultural equipments. Similar restrictions on land use activities apply to areas of high aquifer vulnerability.

New Brunswick New Brunswick enacted the "Well field Protected Area Regulation" under the Clean Water Act as the basis for establishing 'Protection Areas' around municipal well fields. Protection areas (Zones A, B and C) are based on groundwater travel times of 100 to 250-days, 250-days to 5-years, and 5 to 25-years. Different land uses are restricted within each protection area. Within Zone A, prohibited uses/activities include transformer substations, storage of liquid petroleum products, pesticides, fertilizers, livestock grazing or stabling, liquid or dry animal manure composting. Residential uses are permitted but they must be serviced. Existing commercial, industrial and institutional buildings are permitted but no expansions are allowed to any residential or non-residential uses.

In Zones B and C, groundwater may be extracted from the aquifer (quantity limited) by wells that are not municipal wells. Restrictions are relaxed on uses prohibited in Zone $\mathrm{A}$, when they are located in Zones B and C (i.e., liquid manure may be stored, but in a clay lined pit; livestock may be grazed if fenced; limited quantities of petroleum products may be stored; pesticide use is permitted to manufacturer's specifications). 
In Zone $\mathrm{C}$ larger quantities of chemicals may be stored, and fertilizers may be applied. New residential, commercial, and industrial buildings may be constructed if communally serviced or where the number of residents and employees serviced by septic tanks does not exceed 25/ha. Drainage patterns for wetland areas cannot be modified without conducting an impact study on the hydrology and hydrogeology. The province has parallel restrictions to protect sensitive aquifer areas of interest is a maximum floor area size limit of $185 \mathrm{~m}^{2}$ for a single detached dwelling and a prohibition against any conversion of a single to a multiple unit in the highest sensitivity area. In this area, fertilizer application is limited to inorganic applications.

Regional Municipality of Waterloo (Ontario) The Region of Waterloo, where all communities and the rural areas are primarily dependant on groundwater for their water supply source, adopted Official Plan Amendment \#12. This amendment, now approved, provides for wellhead protection through land use restrictions in four "sensitivity areas", which correspond to the time-of-travel within each of the zones. Certain (Category A) uses are prohibited in all four sensitivity areas (i.e., lagoons, land fill sites, disposal of abattoir and rendering wastes, auto wrecking, and salvage yards). An extensive list of uses in Categories B and C are prohibited in Wellhead Protection Sensitivity Areas 1, 2, and 3. Local municipalities are not permitted to redesignate land in local Official Plans for any of the uses prohibited in the respective sensitivity areas.

Oxford County (Ontario) An approach similar to that adopted in the Region Municipality of Waterloo has been taken in Oxford County as part of the current update of the County Official Plan. However, the scope of uses differs somewhat from the Regional Municipality of Waterloo. Activities banned in WHPA's include earthen manure storage facilities, the bulk storage of tires, the refining of petroleum products, the bulk storage of chemicals or hazardous substances (except on-farm storage), the warehousing of cleaning products, pesticides, herbicides and fungicides, and the storage/warehousing of bulk storage of petroleum products. Underground storage tanks, sumps such as dry wells and machine pits and automotive repair pits would not be permitted in the two highest sensitivity rankings, while above ground storage with secondary containment would be permitted. New development on wells and septic tanks would not be permitted in WHPAs, without meeting certain performance requirements including a disclosure report identifying the scope of the use, a detailed hydrogeological study with an associated mitigative plan, and a spill and contingency plan. Intensive livestock operations, manure storage and application are not permitted in sensitivity 2 or 3 WHPAs. 
Alberta, Newfoundland and Prince Edward Island Wellhead protection measures in some other provinces, such as Alberta, Newfoundland and Labrador, and Prince Edward Island, are based on minimum separation distances as opposed to land use restrictions. Distances vary for storage of petroleum tanks (15 to $50 \mathrm{~m}$ ), septic tanks (10 to $16 \mathrm{~m})$, and sewage lagoons $(100 \mathrm{~m})$.

Nova Scotia In Nova Scotia, the Water Act has been used as the basis for establishing 'Protected Water Areas' (PWA), which are equivalent to a WHPA, tailored to individual communities. A three-zone time-of-travel system is used for a PWA. For example, within a PWA, open fires are not permitted (April to October). Restrictions on forestry operations apply on the quantity of timber removed and setbacks of the operation. Chemical pest control products are prohibited in Zone 1 and aerial spraying is barred within a $150 \mathrm{~m}$ radius of a wellhead. Landfill and animal waste disposal is prohibited. The use of any vehicle, except a municipal service vehicle, is prohibited in Zone 1. Peat, gravel, rock and mineral extraction, and agricultural operations are prohibited in Zone 1. Intensive livestock operations in Zones 2 and 3 are permitted where they comply with the provincial animal manure spreading guidelines and where the nitrogen level for all fertilizer applications does not exceed a prescribed standard.

Measures applied as part of a groundwater protection strategy vary across different regions of Canada and the US. Typically, the approach that is adopted depends on local hydrologic and hydrogeologic conditions, soil structure, land use activities, legislative experience, and the importance of water in the public policy agenda.

The most successful approaches depend on a package of protection measures that are both voluntary and regulatory. This is essential since much of the landscape has been developed and municipalities have limited authority to implement retroactive land use controls. Also, the resources may not exist to expropriate or acquire lands or buildings that constitute a potential or actual threat to contamination or which could serve as a buffer area (for instance, in the highest sensitivity area of a WHPA). The development of a Groundwater Protection Strategy should consist of measures which provide an affordable and reasonable level of protection, and which can be adapted to changing circumstances. 


\section{GIS FOR GROUNDWATER PROTECTION}

\subsection{Introduction}

Geographic information system (GIS) is one of the most important tools for integrating and analyzing spatial information from different sources or disciplines. It helps to integrate, analyze, and represent spatial information and database of any resource, which could be easily used for planning of resource development, environmental protection and scientific researches, and investigations.

Many computerized tools have been used for the groundwater assessment, development and overall management in the world. Geographic information systems have emerged in the last decade as an essential tool for urban and resource planning and management. GIS is a userfriendly decision support tool for the monitoring and management of spatially distributed groundwater. The need for integration of information and data is critically important to know the groundwater potential and thereby to design sustainable development strategies which would enable to utilize the resource without affecting the environment.

GIS is a powerful tool for environmental and water resources data analysis and planning. Water resources assessment of a region involves a detailed study of the surface and sub-surface water. To integrate the entire surface and sub-surface data manually requires huge manpower and time. By adopting a GIS platform the result obtained will be faster and more accurate. Their capacity to store, retrieve, analyses, model, and map large areas with huge volumes of spatial data has led to an extraordinary proliferation of applications. GIS stores spatial information and data, which can be overlaid with data or other layers of information into a map in order to view spatial information and relationships. Figure 5 shows an example of watershed data overlays. 


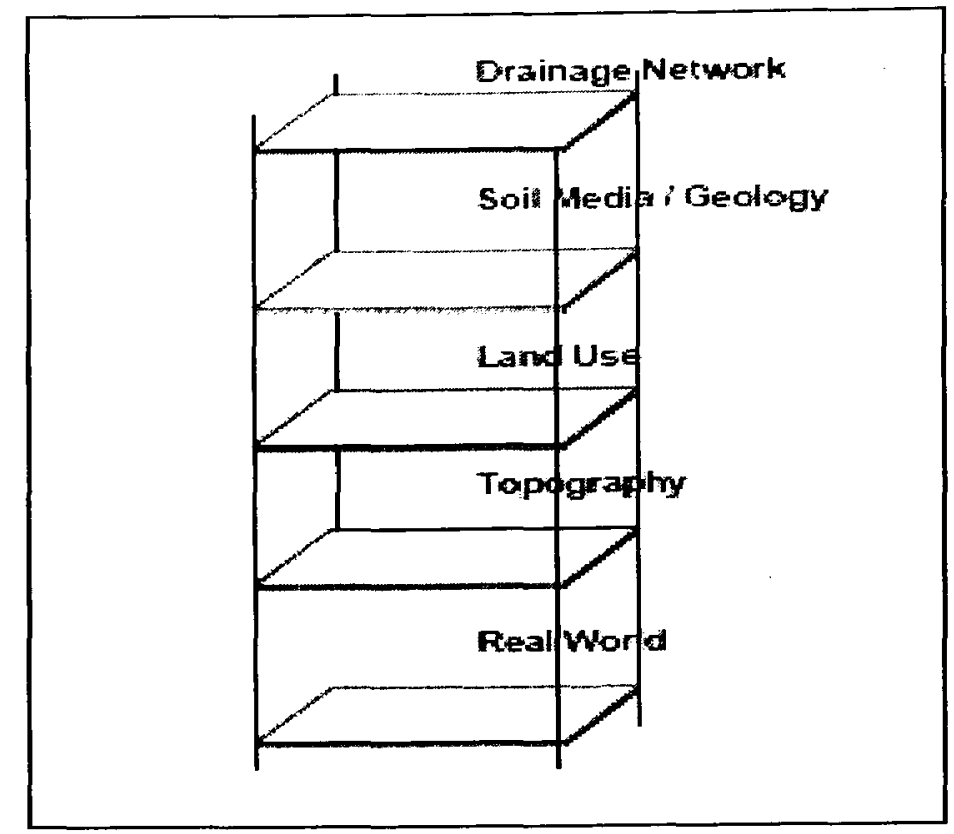

Figure 5 Watershed data overlays

The GIS assisted database system would help to apply groundwater management practices such as proper groundwater resource management in terms of groundwater quality and quantity, integrated management of water, land use and the environment, to optimize pumping rates with respect to the capacity of the aquifer system, and to prevent groundwater quality deterioration through proper monitoring and evaluation.

The GIS has two goals in terms of groundwater management:

- Spatial analysis of phenomena and processes within a watershed; and

- The management of land resources and ecosystems.

GIS provides the opportunity for efficient and improved processing and analysis of geographical information. Spatially varied information are, such as precipitation, evaporation, land use, soil properties, and soil moisture contents, etc. Environmental data are needed for one or more of the following reasons (Harmancioglu et al., 1998; Varma, 1996):

1. To identify the nature, trends, and anomalies in characteristics of environmental processes in order to better understand these processes.

2. To assess the effects of natural and human-made factors upon the general trends in environmental processes. 
3. To evaluate the effectiveness of pollution control measures.

4. To asses the appropriateness of environmental quality standards.

5. To assure compliance with established quality standards and enforcement of quality control measures.

6. To conduct environmental impact assessment.

7. To monitor and assess the general quality of the environment at regional to global scales.

8. To develop, calibrate, and validate models of environmental processes.

\subsection{GIS Data}

Data is the core of any GIS. The most important and often the most expensive part of an effective GIS on any application is data that is specially coded to include information about location. The availability of appropriate and adequate environmental data, and the full extraction of information from collected data, is important concerns. These data generally come in different format and from various sources and measurements. Spatio-temporal data are collected primarily by means of field surveying, instrumentation, photogrammetry, and remote sensing. Field data collection using sampling, surveying, and GPS instruments may be required for gathering geospatial information. The examination and organization of data into a useful form produces information, which then enables appropriate analysis and modeling.

Two important concepts that apply to data quality are precision and accuracy. Data precision refers to the number of decimal places used to represent measurements of such things as geographic coordinates, chemical concentrations in ground water, metrological observations, etc. Accuracy is a measure of how closely data represents reality within specified tolerances. The appropriate level of data precision and accuracy will depend on the data type of application and analysis for which the data are being used.

3.2.1 GIS Data Types Data used for GIS analysis mainly spatial data, attribute data, temporal data and metadata. Spatial data contains the location and shape of geographic features such as roads, land parcels, vegetation stands on the earth surface etc, which may be discrete or continuous. Discrete features are individually distinguishable features that do not exist between observations. Discrete features include points (e.g., wells), lines (e.g., roads), and areas (e.g., land-use types). Continuous features are features that exist spatially between observations. Examples of continuous feature are elevation and precipitation. A GIS represents these spatial 
features on the earth's surface as map features on a plane surface. The locations of spatial features on the earth's surface are based on the geographic coordinate system with longitude and latitude values, whereas the locations of map features are based on a plane coordinate system with $\mathrm{x}, \mathrm{y}$ coordinates.

The data model defines how spatial features are represented in a GIS. There are two basic approaches to storing spatial information such as (1) vector data model and (2) raster data model. The vector data model uses points and their $\mathrm{x}$; $\mathrm{y}$ coordinates and sometimes $\mathrm{z}$ coordinates for height, to construct spatial features of points, lines and areas. The raster data model uses a grid and grid cells to represent the spatial variation of a feature. Both systems are georeferenced, meaning that the attribute information is tied to a specific location on the earth's systems. Figure 6 shows the data using $\mathrm{x}, \mathrm{y}$ coordinates to represent point on the left, line and vector data model using polygon features on the right.
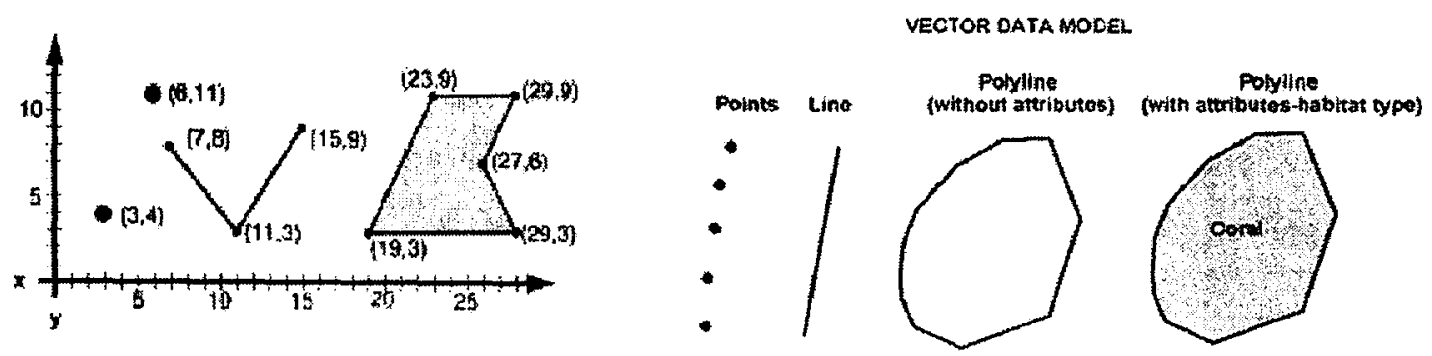

Figure 6 Vector data model

(Source: [Booth.B., 2001])

Figure 7 shows the raster data model uses cells in a grid to represent point features on the left and raster data model on the right.
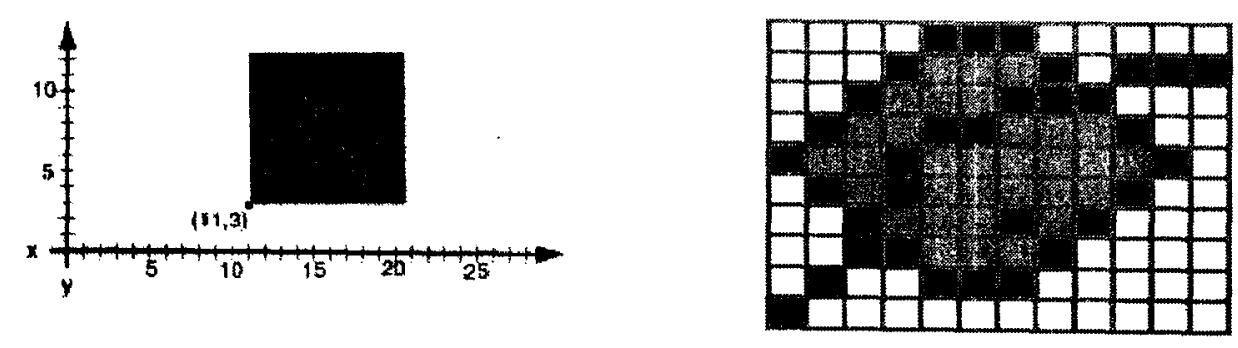

Figure 7 Raster data model

(Source: [Booth.B., 2001]) 
Attribute (tabular) data describe the characteristics of spatial features. For raster data, each cell has a value that corresponds to the attribute of the spatial feature at that location. For vector data, the amount of attribute data to be associated with a spatial feature can vary significantly. Temporal data generally exhibit variation and change over time. For example temperature, wind speed and direction, and precipitation as recorded by weather stations. Metadata are information about data, and as such, are most useful when data are transferred between users. Typical metadata might include such things as map projections, source materials and date acquired, and how the data was processed. The absence of metadata severely limits the utility of any spatial data.

3.2.2 GIS Data Formats The term file format refers to the logical structure used to store information in a GIS file. File formats are important in part because not every GIS software package supports all formats. If it is required to use a data set, but it isn't available in a format that GIS supports, then it have to find a way to transform it, find another data set, or find another GIS.

Almost every GIS has its own internal file format. These formats are designed for optimal use inside the software and are often proprietary. They are not designed for use outside their native systems. Most systems also support transfer file formats. Transfer formats are designed to bring data in and out of the GIS software, so they are usually standardized and well documented. ArcGIS can read a variety of file formats. Many of these are come from older versions of the software. Some of these file formats is described below:

Shape files Shape files are vector data files developed for the early version of ArcView and have been carried over into ArcGIS. They do not store topology and they can contain only one feature class. They may contain points, lines, or polygons, and their attributes data are stored as dBase files (extension.dbf). A shape file is actually a collection of files on the disk, with a common name but different extensions (e.g., road.shp, roads.dbf, roads.shx)

Coverage It is the vector data format developed for Arc/Info, and the oldest of the data formats. They are topological data sets and usually contain multiple feature classes. Coverages are also composed of multiple files on the disk and even spread data among multiple folders. 
Geodatabase It is the newest spatial data format. They can contain multiple feature classes, including tables not linked with spatial data. They are stored as a single database files, and require an underlying database system to operate. They can store topological relationships between feature and feature classes. Two types of geodatabases are used by ArcGIS such as personal geodatabases and multiuser geodatabases. Personal geodatabases are based on Microsoft Access database technology.

Layer It does not contain spatial data. Instead they reference a spatial data file and store information on how it is to be displayed. Layers can be created to store a set of symbols for displaying a particular datasets, and can be used over and over. Several layers can be combined to form a group layer.

Image This data ranges from satellite images and aerial photographs to scanned maps (maps that have been converted from printed to digital format). Image data offers a quick way to get spatial data for a large area and is more cost and time-effective than trying to collect layers of data like buildings, roads, lakes etc, one at a time. Image data is the best choice if it is need to add a point of reference to vector data without attaching additional information.

Table A table can exist as separate data object that are unassociated with a spatial data set. These are called standalone tables. They may be stored in dBase format (.dbf) or as a comma-delimited text file.

Grids A grid is a raster format developed ESRI (Environmental Systems Research Institute) and used with ArcView, Arc/Info GRID, and ArcGIS software. Grids can be manipulated and analyzed by the ESRI software Spatial Analyst or Grid.

DEM (Digital Elevation Model) It is a raster format used by the USGS to record elevation information. Unlike other raster file formats, DEM cells do not represent color brightness values, but rather the elevations of points on the earth's surface.

CAD drawings Data sets created by CAD programs can be read by ArcGIS, although they cannot be edited or analyzed unless they are converted to shape files or geodatabases. A CAD file may contain multiple feature classes, which correspond to the layers of the drawings, and can be opened separately and viewed just like feature classes in a coverage or a geodatabase. One can also access CAD drawings, which portray all the features in the CAD file with preset symbols. 
TINs Triangulated Irregular Networks that store surface information, such as elevation, using a set of nodes and triangles.

Internet Servers Many organizations now make data available over the Internet.

3.2.3 GIS Data Sources A heightened awareness of the environmental problems has developed over the past decade and this has spurred a need for reliable geospatial data to enable better understanding of environmental processes and their impacts. Environmental models have also undergone changes and these have created new requirements for geospatial data. Similarly, increased attention in the 1990 s to the analytical and environmental modeling capabilities of GIS has generated additional requirements for geospatial data. In view of the critical role data plays in any kind of spatial modeling, the sources of geospatial data is very vital for an environmental modeling project.

Existing data sources may be in analog form (such as traditional printed maps) or as digital files. The readily available sources of digital data are very numerous. reliable sources of digital datasets are Geobase (by Canadian Council on Geomatics), GeoGratis (by Natural Resources Canada), Ontario Basic Mapping data (Geography Network and Ontario Ministry Natural Resources), GeoConnections Discovery Portal (Canadian Geospatial Data Infrastructure), Geological Survey of Canada, Census of Canada, Geography Network (ESRI Canada's portal), GIS Data Depot (GeoCommunity) etc.

Another aspect in GIS data is the use of topographic information for the development of Digital Elevation Models (DEM). The USGS produces a number of data products that include Digital Line Graphs (DLGs), Digital elevation models (DEMs), Digital Orthophoto Quads (DOQs), Geographic Names Information Systems (GNIS), and Digital Terrain Elevation Data (DTED). The ESRI Web sites for GIS data are http://www.esri.com/data/index.html. The Federal Geographic Data Committee (FGDC) has established the National Geospatial Data clearinghouse, as well as standards for the minimum set of metadata necessary to adequately describe geospatial data, thereby facilitating its use by others. Invariably these data have to be processed and manipulated to make them amenable for use in modeling and analysis.

3.2.4 GIS Data Conversion and Integration Data conversion is still an important task in any environmental projects using GIS and constitutes a major portion of the cost and time of projects. Digital data is created by the process of converting existing maps or graphic documents into an 
appropriate digital form using digitizing or scanning methods. Map conversion projects need to pay attention to scale, level of generalization, datum, coordinate system, projection, data of source, and accuracy (Fisher, 1991). One of the strengths of GIS is the ability to integrate data from diverse sources. An environmental application or modeling effort may require the use of traditional maps containing point, line, and polygon features, as well as grids, satellite images, digital elevation models (DEM), digital orthophotos, and scanned data files. Integrating images (raster data) with feature coverages (vector data) has become increasingly common thanks to improvements in GIS data handling capability. Integrating data from diverse sources requires that attention be given to format, scale, projection, coordinate reference system, resolution, precision, and accuracy. Incompatibility may propagate error in GIS and environmental modeling applications (Carlotto, 1995; Heuvelink, 1990).

\subsection{GIS Modeling Tools}

The most successful applications of GIS can be identified in four areas:

\section{Mapping;}

2. Data pre-processing;

3. Modeling; and

4. Policy formulation.

Hydrologic modeling is the use of physical or mathematical techniques to simulate the hydrologic cycle and its effects on a watershed. The ongoing development of GIS techniques integrated with hydrologic models provides powerful ways to allow us to understand, to visualize, and to analyze hydrologic processes (Singh and Fiorento, 1996). Hydrologic models that have a spatial component can benefit greatly from the use of GIS. Artificial divisions of watersheds into surface water hydrology, vadose zone hydrology, and groundwater hydrology will be abandoned in the future as more research is undertaken.

In recent years various hydrological modeling options have become available in commercial GIS packages. Additionally some hydrological packages have a live link with GIS packages and to perform specific hydrological operations. Comprehensive GIS packages are becoming available that are capable of managing and processing massive quantities of data, and will, therefore, provide a means of integration on a watershed basis. For example, GIS World (1990) lists over 160 commercially available GIS packages (Kite et al, 1996). 
ArcGIS is an integrated collection of GIS software products for building a complete GIS. ArcGIS enables users to deploy GIS functionality wherever it is needed in desktops, servers, or custom applications; over the Web; or in the field. Among them ArcGIS Desktop is the most powerful GIS product available today. An extensive collection of desktop extensions provides additional capabilities. ArcGIS Desktop is a suite of integrated applications including Arc Map, Arc Catalog, Arc Toolbox, Model Builder, and Arc Globe. Using these applications in unison, can perform any GIS task, simple to advanced, including mapping, geographic analysis, data editing and compilation, data management, visualization, and geoprocessing.

ArcGIS provides a comprehensive set of geoprocessing tools and a new framework for working in hydrologic modeling. In Arc toolbox the spatial analyst tools contain hydrology toolset for analyzing terrain surfaces and modeling how water will flow across them and groundwater tools used to perform rudimentary advection-dispersion modeling of constituents in groundwater and applied individually or used in sequence to model and analyze groundwater flow.

In ArcGIS 9 the model builder interface provides a graphical modeling framework for designing and implementing geoprocessing models that can include tools, scripts, and data. Models are data flow diagrams that link together a series of tools and data to create advanced procedures and work flows. These tools perform multiple geoprocessing operations to study groundwater contaminations issues of a watershed before reaches to aquifer. Model builder is a productive mechanism to share methods and procedures with others within, as well as outside, any organization. Arc Toolbox and Model builder, available in all ArcGIS Desktop environments, are used for geoprocessing and spatial analysis such as suitability modeling.

\subsection{GIS Initiatives and Applications at Niagara}

The NPCA relies heavily on spatial data, the bulk of which is topographic, environmental or natural resources based land information, to support or directly carry out most of its day to day tasks. GIS technology has been deployed throughout the NPCA over an ever increasing broad base of applications and many key Authority programs now depend on its support for efficient data management, mapping, and powerful analytic capabilities. As a result the NPCA continues to integrate the Geographic Information Systems by developing data and applications that serve its business need in order to make informed management decisions. In effect, the Authority has been implementing GIS and geomatics technologies to support its programs with spatial information, 
improving the efficiencies of day to day operations with digital mapping products and spatial information, improving the efficiencies of day to day operations with digital mapping products and spatial analyses since 2001 .

The NPCA GIS program strives to provide high quality, local scale environmental and natural resources geographic data of its jurisdiction to its own programs and its partners in conservation. Supporting this role is the transformation of data holdings within the NPCA "GIS Data Repository" into a published and catalogued Watershed Management Information System (WMIS). This WMIS will be the combination of a Hydrologic Information System (HIS) of water resources related data, a Natural Heritage Information System (NHIS) of terrestrial cover and habitats data, and other sub data models of various application specific information (i.e., a spatial database for facilities and asset management of the Authority's Conservation Areas), all integrated together in a dynamically modeled, relational data storage system. Some examples of applications of GIS at NPCA are given below:

Flood Plain Mapping The NPCA is busy updating its regulatory flood plain hardcopy mapping into digital spatial data. Where existing mapping exists hardcopy sheets have been scanned and georeferenced in ArcGIS using the georeferencing toolbar so that flood lines could be heads up digitized for capture. In other areas where there is no existing floodplain mapping available the Authority is currently undergoing engineered flood studies with GIS support to generate the new regulatory flood lines.

A high resolution digital elevation model (DEM) of 10 meter grid mass point spacing and detailed select point density 3D break lines with horizontal and vertical control accuracies that are suitable to generate $1 \mathrm{~m}$ contours and support 1:2000 scale topographic mapping is being used with the current beta release of HEC's GeoRAS for ArcGIS to extract spatial and hydraulic inputs of cross section and stream data from a TIN representation. Numerical modeling outputs are also processed in ArcGIS to render the flood surface profiles and derive the regulatory line. Figure 8 shows the application of GIS at NPCA for flood plain mapping. 


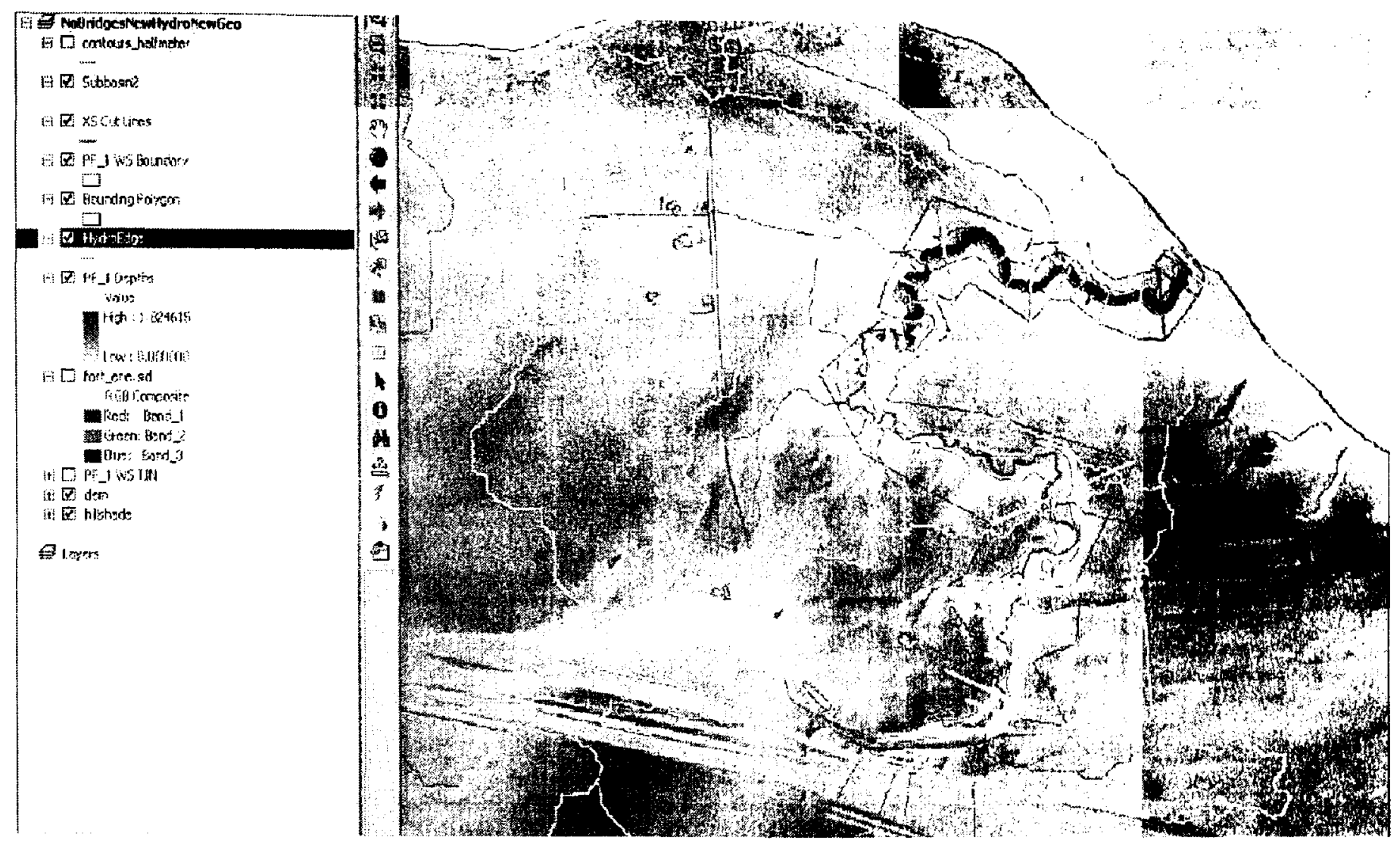

Figure 8 Flood plain mapping

Generic Regulations Mapping A recent update to the Conservation Authority's Act in Ontario has amended what types of lands a Conservation Authority are able to regulate under a new Generic Regulation. As a result, GIS staffs are currently compiling floodplain, erosion, valley and shoreline data to analyze and appropriately map all areas within the NPCA's jurisdiction supporting the new regulations as required. Slope, contour, break line, flood line, other pertinenent data and buffering operations to determine setback allowances will form the basis of the analyses (see Figure 9). 

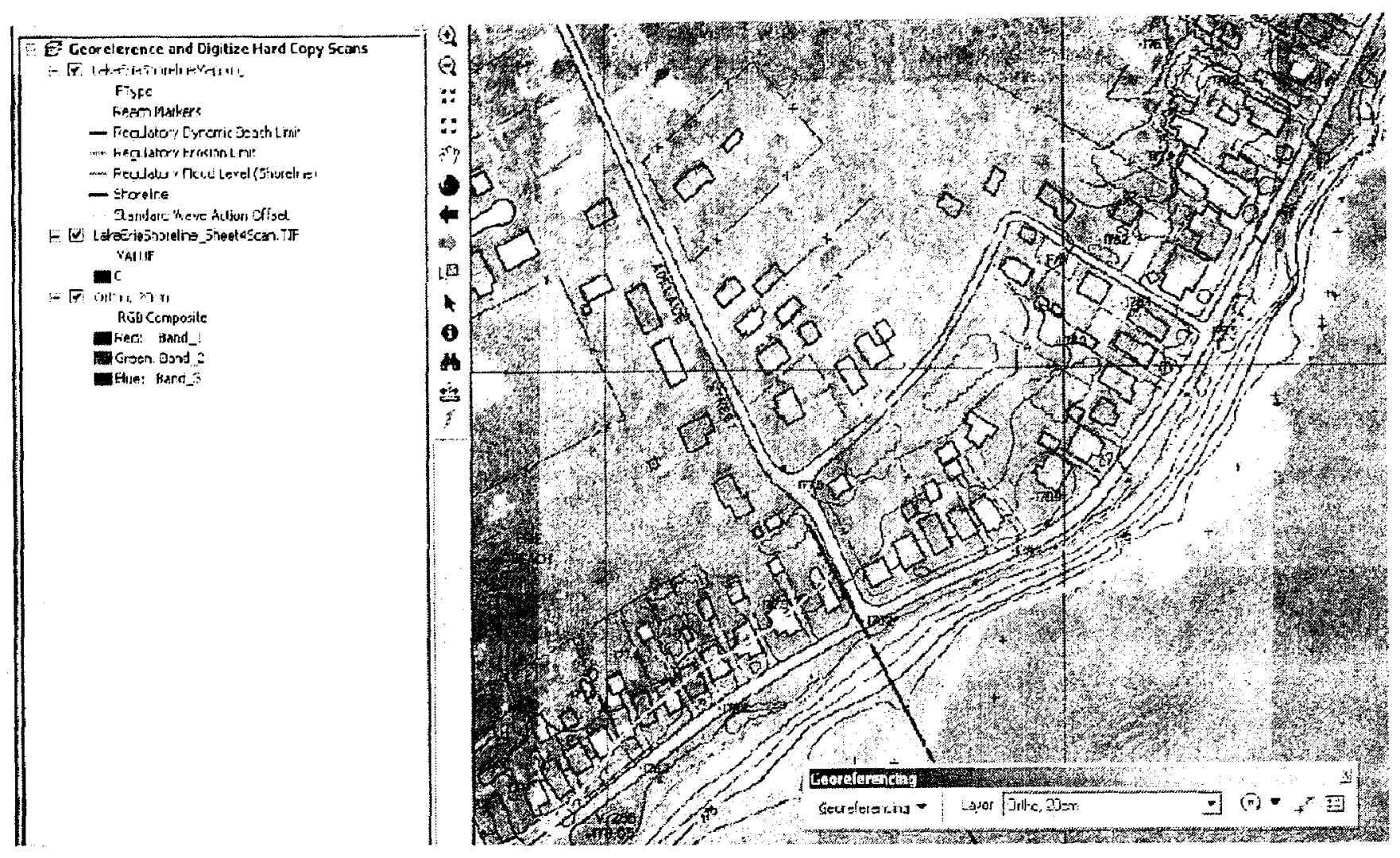

Figure 9 Generic regulations mapping

Hydrologic Information System (HIS) As an indirect result of the digital floodplain mapping process the NPCA is creating a new 1:2000 scale hydrography and a hierarchy of drainage areas (from catchments of any desirable size and tesselation depending on the management need, to sub watersheds, watersheds and basins) with the ArcHydro tools and data model. This data will serve as the framework from which the Authority's corporate GIS will be based. Water related databases such as municipal drain classification and fish habitat type etc. will build onto and spatially reference the data structure. This development will provide the NPCA with an updated inventory of watercourses and water bodies and a scale more suitable for its management needs, ensuring quality data and mapping for its water resource responsibilities and applications. With the advent of additional datasets as a result of a current and regional groundwater study and aquifer characterization, the NPCA will have a digital and spatial Hydrologic Information System that will account for the entire hydrologic cycle (see Figure 10). 

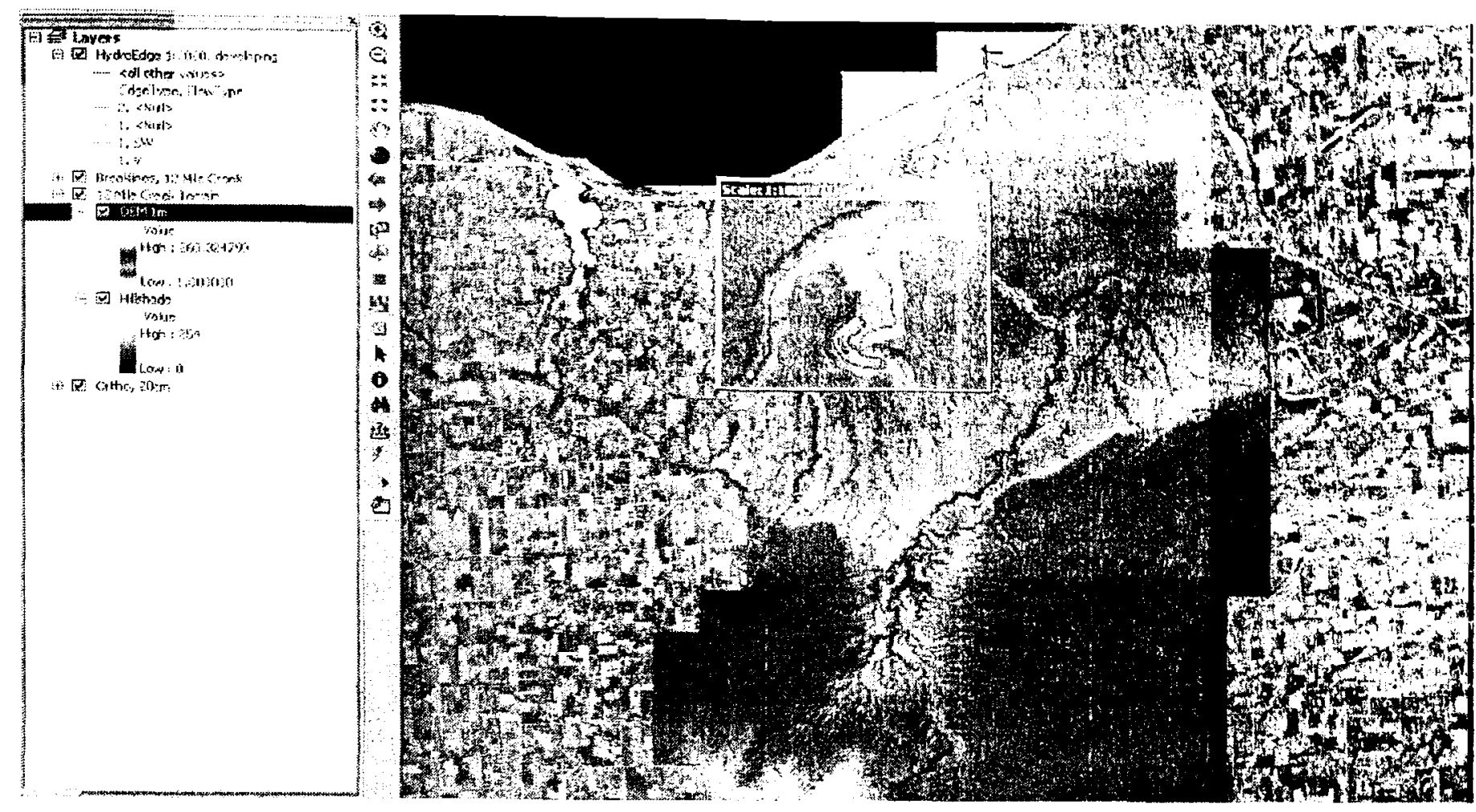

Figure 10 Hydrology mapping

Restoration Applications The NPCA continues to use GIS to develop mapping products and analyses that support the stewardship based efforts of its Restoration Program. Specifically GIS has assisted staff in assessing the status (statistics) of various natural areas and habitat types on a sub watershed basis, helped develop a spatial database to document, map and tally completed projects to monitor and report restoration success, and to target restoration opportunities with suitability mapping products that ensure the most efficient use of grant dollars so that projects are implemented where the highest environmental benefits and gains will be experienced.

The NPCA currently implements ESRI's ArcGIS desktop GIS software. Specifically, the Authority maintains a small collection of ArcView licenses supplemented by an Arc Info, Spatial and 3D Analyst licenses. As an industry leader in GIS technology, ESRI products help the Authority remain highly compatible with its federal, provincial, municipal, and other non government organizations counterparts in conservation. ESRI software is also a natural choice for the Authority as a water management agency since ArcGIS is widely used in the forefront of research that is developing standard geographic data models and associated tools to extract and relationally store spatial inputs from GIS data for hydrologic and hydraulic numerical models, groundwater protection model, and other water resources applications. 


\section{GROUNDWATER PROTECTION MODEL USING GIS TOOLS}

\subsection{Study Area}

The Regional Municipality of Niagara is an area covering 12 unique and distinct local municipalities located in southern Ontario in Canada (RMN, 2006). The Niagara region is a very diverse municipality and covers 1896 sq. km (715 sq. miles) (The Regional Municipality of Niagara, 2006). The municipalities are varying from the larger populated cities of St. Catharines and Niagara Falls with their urban intensive features, to Wainfleet and West Lincoln with a more rural or natural area setting. The total population within the area of jurisdiction is estimated as 460,000 .

In this project the study area includes Niagara-on-the-Lake, Niagara Falls, Welland, Thorold, Fort Erie, and St. Catharines (see Figure 11 for a map of the study area). The watershed is drained primarily by the Welland River, Twelve Mile Creek, Twenty Mile Creek and Forty Mile Creek, with a number of smaller watercourses draining into Lake Ontario and Lake Erie. 


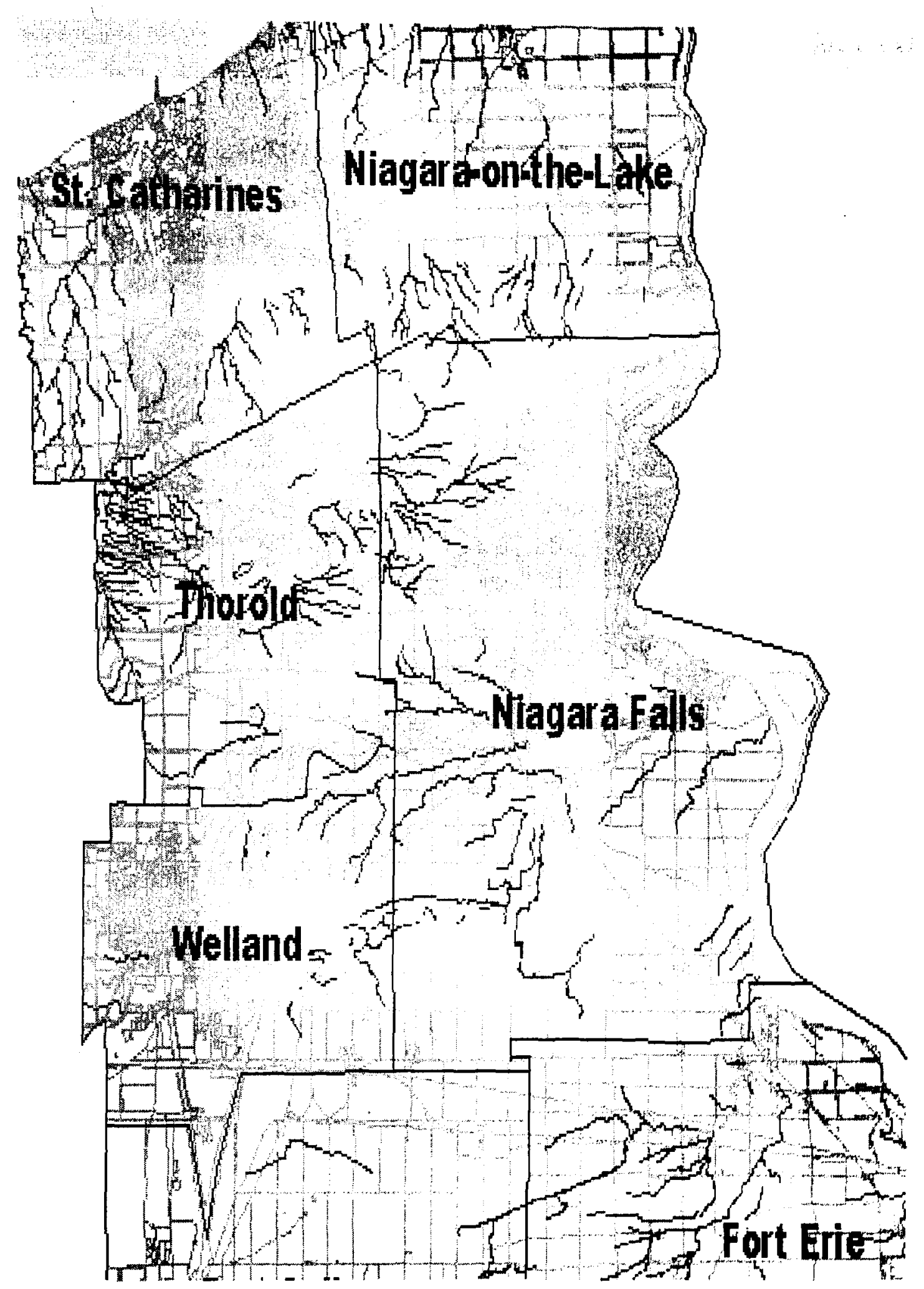

Figure 11 Study area 


\subsection{Data and Data Sources}

A proper study and investigations rely on site-specific data and analysis. In order to build a groundwater protection model of the study area the following data is necessary:

- Base map;

- Land use data ;

- Slopes; and

- Stream data.

Municipality's data, land use polygon shape data, and stream polygon shape data are shown in Table 4 obtained from Can Map Route Logistics 2005.3 (Ontario) through Ryerson University library geospatial resources.

Table 4 List of datasets used

\begin{tabular}{|c|c|c|c|}
\hline Subject & File Name & Format & Description \\
\hline Land Use & ONlur.zip & Shape file & $\begin{array}{c}\text { Types of land as agricultural, } \\
\text { commercial, industrial, residential etc. }\end{array}$ \\
\hline Municipalities & ONmun.zip & Shape file & Boundaries \\
\hline Hydrography & ONwlp.zip & Shape file & Rivers, Creeks, Lakes \\
\hline
\end{tabular}

The slope data will be created from digital elevation model (DEM) datasets of the proposed study area. The DEM data is found from GeoBase. GeoBase is a federal, provincial, and territorial government initiative that is overseen by the Canadian Council on Geomatics (CCOG). It is undertaken to ensure the provision of, and access to, a common, up-to-date and maintained base of quality geospatial data for all of Canada.

\subsection{Data Preparation}

Before going through the Model Builder window for building the model, the dataset should be prepared according to the model requirements. In this project to build the groundwater protection 
model all necessary dataset should be stored into a personal geodatabase feature class in Arc catalog. To do so all dataset should be in the same scale and same format.

Elevation of the study area in raster data format is obtained from DEM data (shown in Figure 12) and then get slope raster data using spatial analyst extension. The scale of this DEM data match with the other polygon shape data those are shown in Table 4. Then classified this slope raster data and converted into slope polygon data. Using hydrology tools of Arc GIS 9, watershed data is found. After that all dataset are obtained as same format i.e., vector data format.

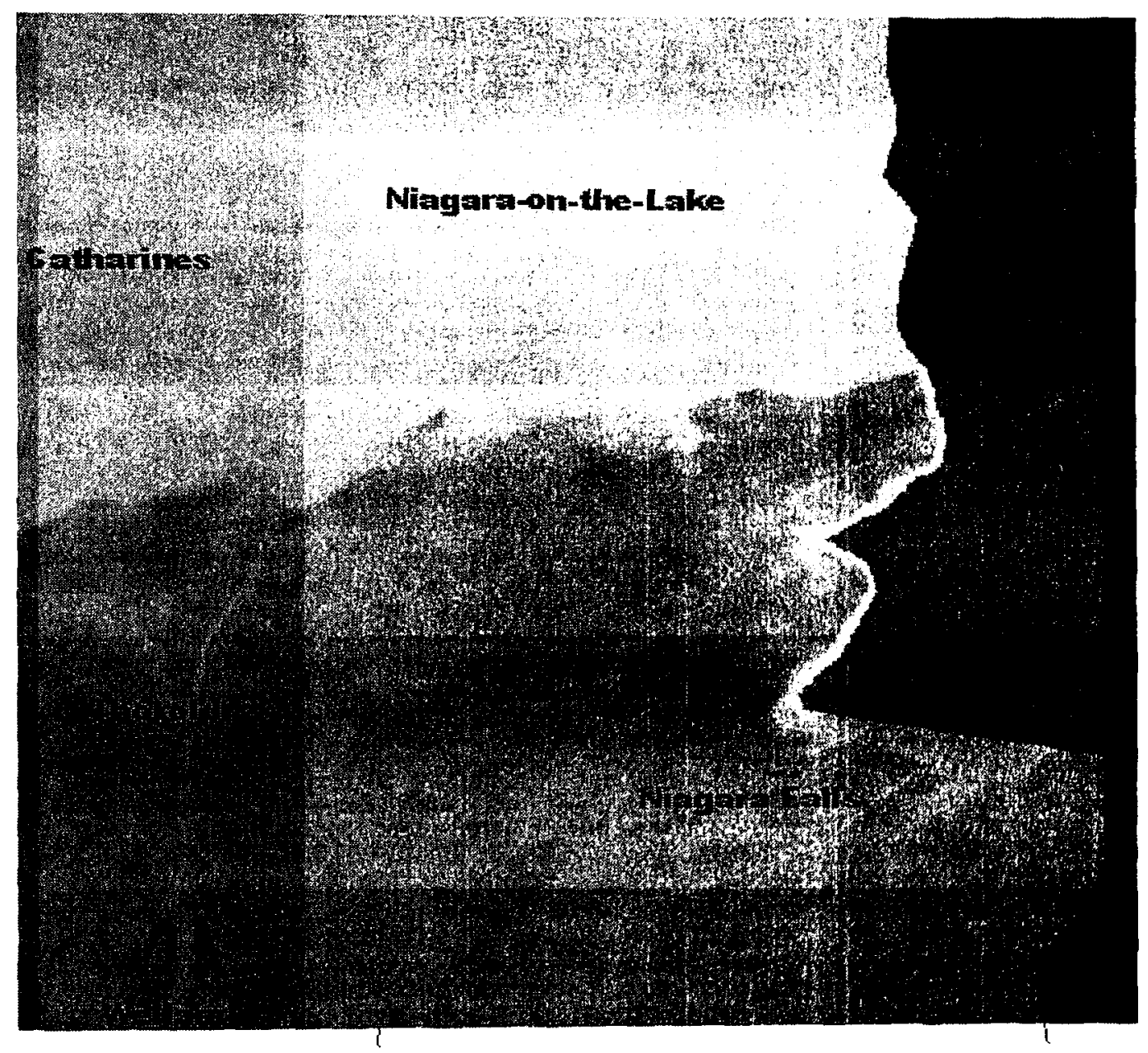

Figure 12 Elevation data of the study area

As the scale of all the dataset are same and at large scales as 1:50,000, so, it isn't needed to convert the scale. Then all the vector datasets are imported in personal geodatabase feature class in ArcCatalog to build the model through the model builder window. Figure 13 shows the personal geodatabase feature class in Arc catalog named Niagara.mdb. 


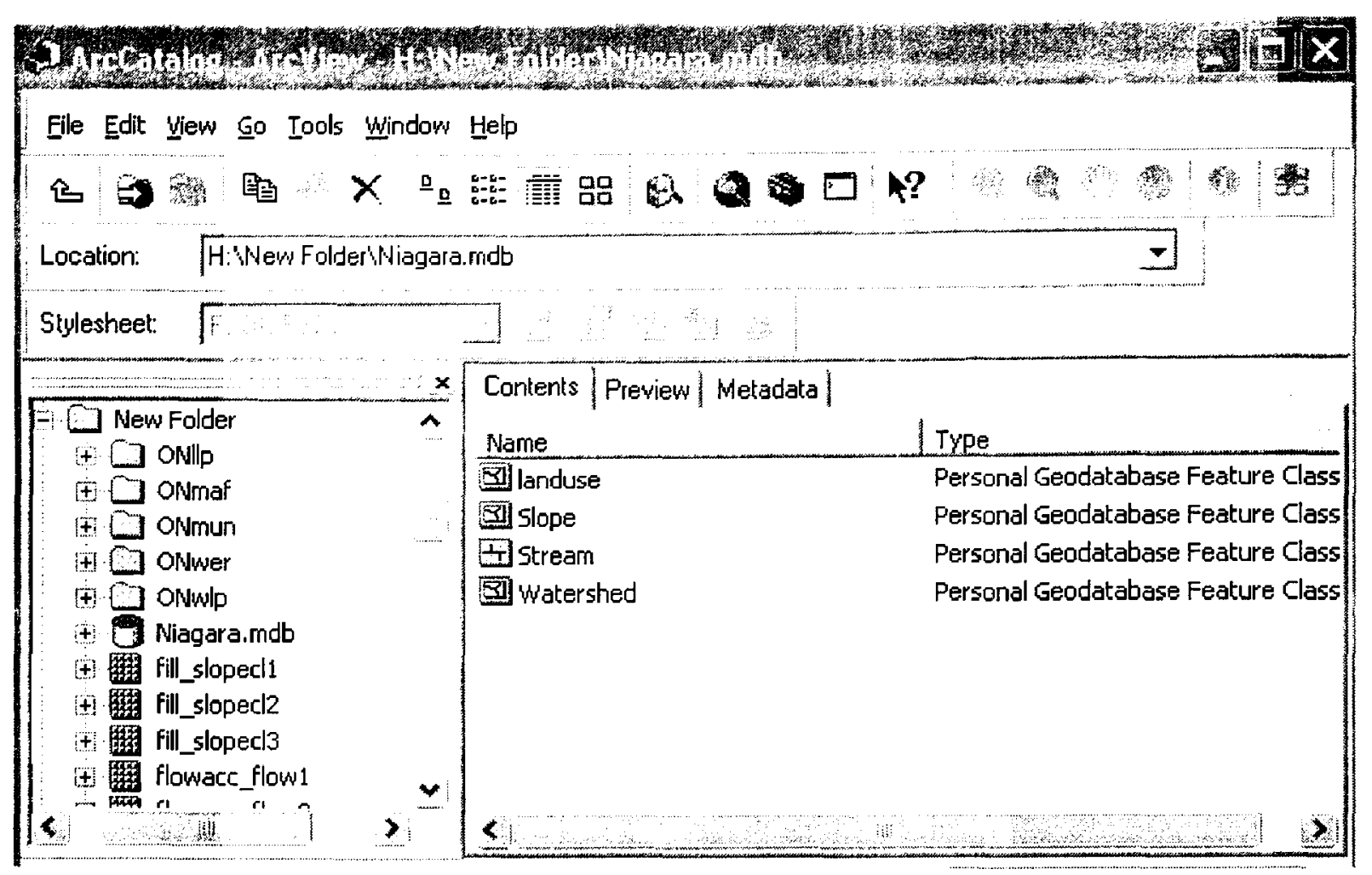

Figure 13 Personal geodatabase feature class - Niagara.mdb

\subsection{Methodology}

The entire work of the proposed project can be basically split into the following steps: (1) collection and preparation of required datasets, (2) development of the groundwater process model through the use of collected data, (3) running, testing, and calibrating / validating the model, and, (4) develop the final groundwater protection model of the study area.

The analysis was performed using the program ArcGIS. In ArcGIS 9 from Arc toolbox window a model can be built from one or more processes in the Model Builder window. The model diagrams are viewed and edited in the Model Builder window. A process is formed by connecting various component elements for input dataset, tools, and output dataset. To open the Model Builder window, a new toolbox is made in the Arc toolbox and a suitable name is given as Niagara groundwater protection model. Project data elements are visual representations of geographic input dataset that exists before the model runs. Add all layers in the ArcMap as illustrated in Figure 14. 


\section{Layters \\ $\theta \square$ DNinum clip \\ $\boxminus \square$ Niagara Watershed ए \\ $\square$ Niagarastream \\ = \\ $\square \square \stackrel{\text { slape }}{\square}$ \\ 实}

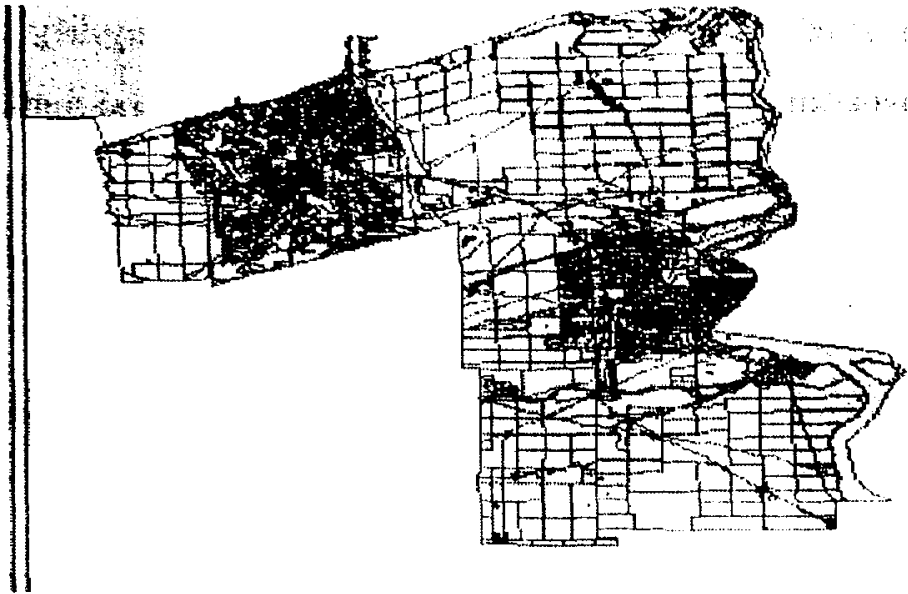

Niagara Land use

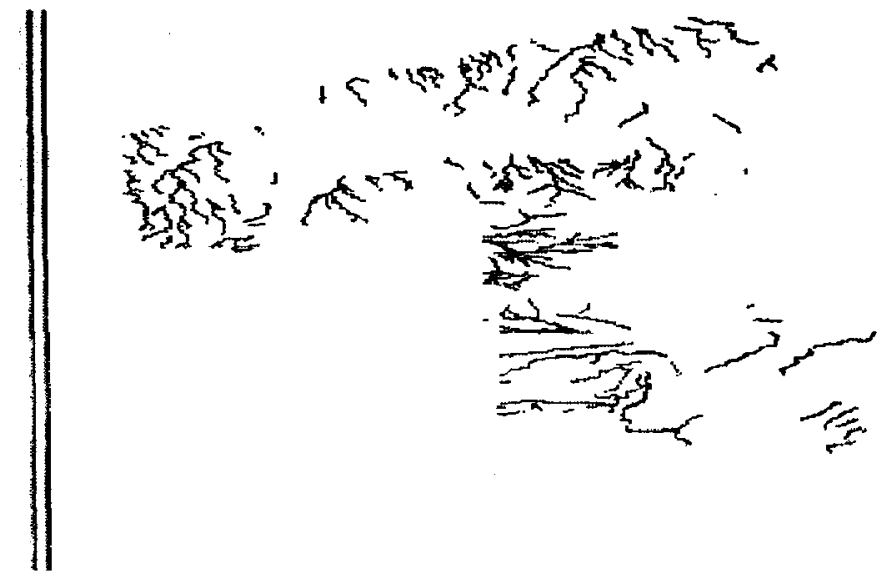

\begin{aligned} & \hline$\$$ Layers \\ &-$\square$ Ormun_Clip \\ &$-\square$ Niagara Watershed \\ &$\square \square$ Niagarastream \\ &$\square \square$ Niagaralanduse \\ &$\square \square$ Slope \end{aligned}

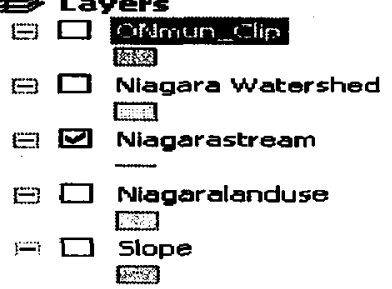

Niagara Stream

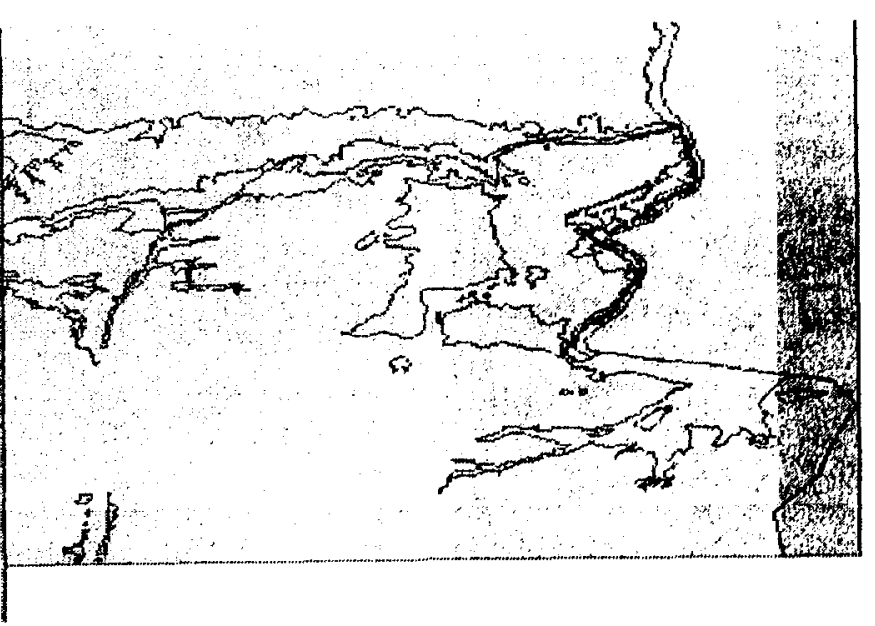

Slope

Figure 14 Natural and landuse layer of study area. 
The tool elements on the model builder window signify the operations to be performed on the input dataset such as watershed, slope, stream, and land use dataset. The model output data elements represent derived data elements that actually serve as input data for other processes. The model organizes clip, intersection, and buffering processes that actually performed on the four geodatabase feature classes: watershed, slope, stream, and landuse to identify crop fields on steeply sloping land near a stream because groundwater contamination in the study areas is caused by agricultural chemicals.

When all geoprocessing operations and SQL expression are ascribed of a model, the model is ready to run. The process model is shown in Figure 15. The default elements colours are blue for project data, yellow for tools, and green for derived data elements. When the model is run, the tool element for each active process turn red and status messages are appeared on the screen.

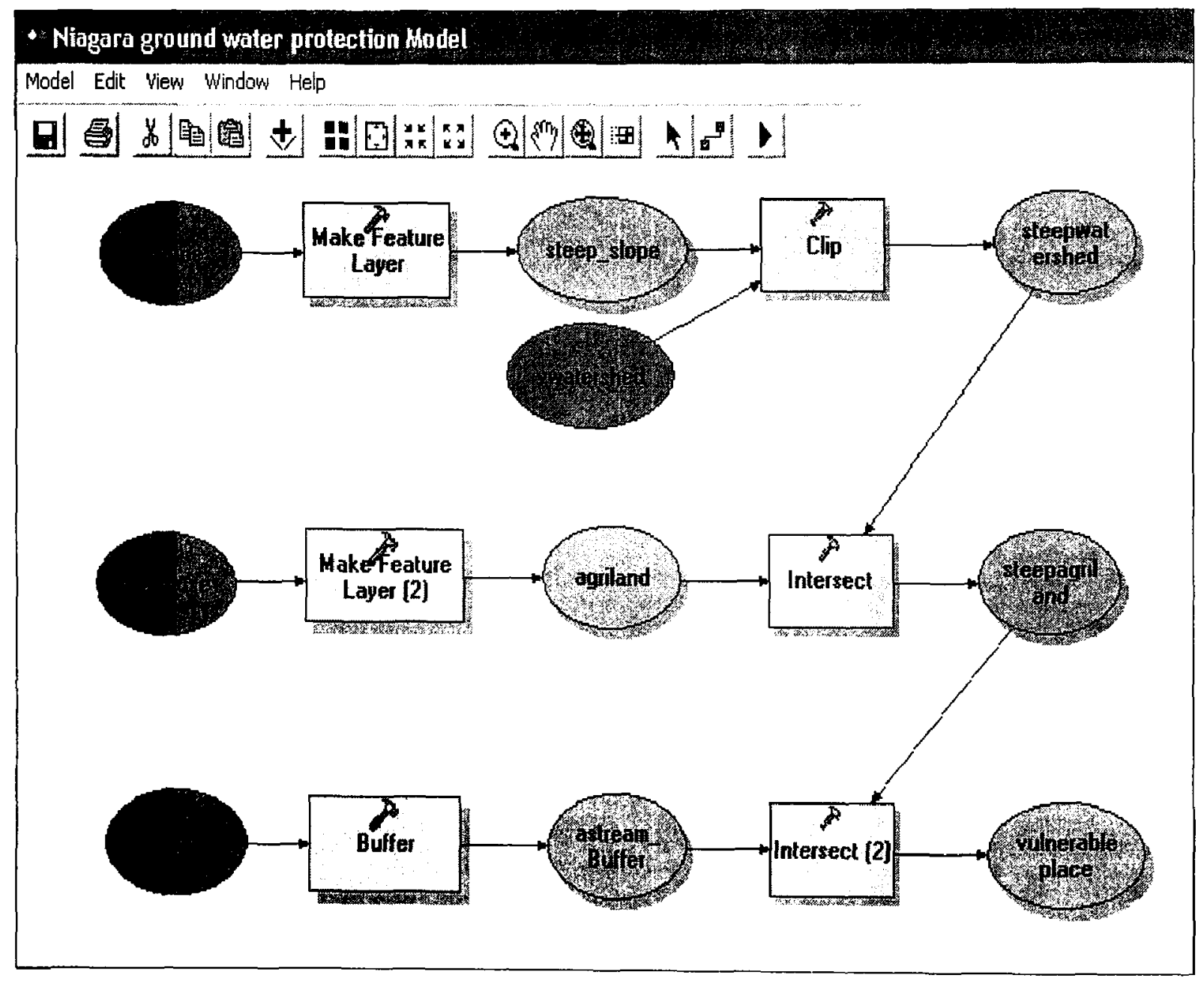

Figure 15 The process model 
Through the visual model-building interface, proposed analyses are more easily translated into ordered a step which is defined as the process model. The process model allows data and tools to be linked together in a user-defined sequence that structures automated geoprocessing tasks such as buffering, converting, overlaying or selecting data. The developed process model are viewed and edited in the Model Builder window. This is basically the main benefit as different analyses can be performed by changing the value of parameters in the query builder tools and effective decision can be made quickly.

\subsection{Analysis}

Basically a big percentage of study area is open land and used for agricultural purpose. The study area also exhibits karst geology, which is characterized by caves, sinkholes, and many surface streams. Karst systems are vulnerable to contamination. To assess the status of the study area as an agricultural area from a resource perspective, three main factors are considered: physiography, soil capability, and climate. The combination of soil characteristics, climate, access to water, and topography, the area become a unique area of specialty crop production. In these vast agricultural areas for the growth of the crops, mineral fertilizer and animal manure and to control unwanted plants and destructive insects, pesticides are mostly used. The run-off of this area infiltrates through the permeable soils and possibly recharges an aquifer or contributes water to a pathway delivering water to an aquifer. Also, unfortunately most of the runoff occurs during rainy season and this runoff from steep-sloped areas drain into the nearby stream. So, runoff from steep-sloped crop fields is one likely source of these agricultural chemicals and defining these areas appropriate control measures can be taken.

Data collection and conversion are an important task in this project. As groundwater contamination is significantly caused by the agricultural chemicals, open area which is mainly agricultural land is taken into consideration for this study. The types of data that are required in this study are slope data, stream data, watershed data, and land use data. The watershed data and slope data are created from the DEM data and the agricultural data from land use data. The DEM data are obtained from GeoBase and the rest of the data were acquired from Can Map Route Logistics 2005.3 (Ontario) through Ryerson University Library Geospatial Resources at a scale of 1:50,000. In the process model agricultural land is intersected with the steep slope and watershed feature class. Finally to identify the most vulnerable contaminated sites, the agricultural lands that 
are located on the steep-slopes and within a certain stream buffer are intersected. Some analyses are performed to change the value of two parameters slope and stream buffer distance in the query builder tools and different scenarios of the model are made and develop for find out the most appropriate one.

Scenario I: At first the buffer distance changes to 500 meter and the slope value remain as the original slope as 5-10 degree. In this case, the agricultural land that is located on steep-slopes and within this stream buffer is most vulnerable to contamination as the most of the run-off these area are responsible for groundwater contamination through infiltration and discharges to the nearby streams. But, the buffer distance 500 meter around the stream surface is comparatively increase redundant cost of protection measures than 300 meter buffer distance around the stream surface. Figure 16 shows the display map for this scenario.

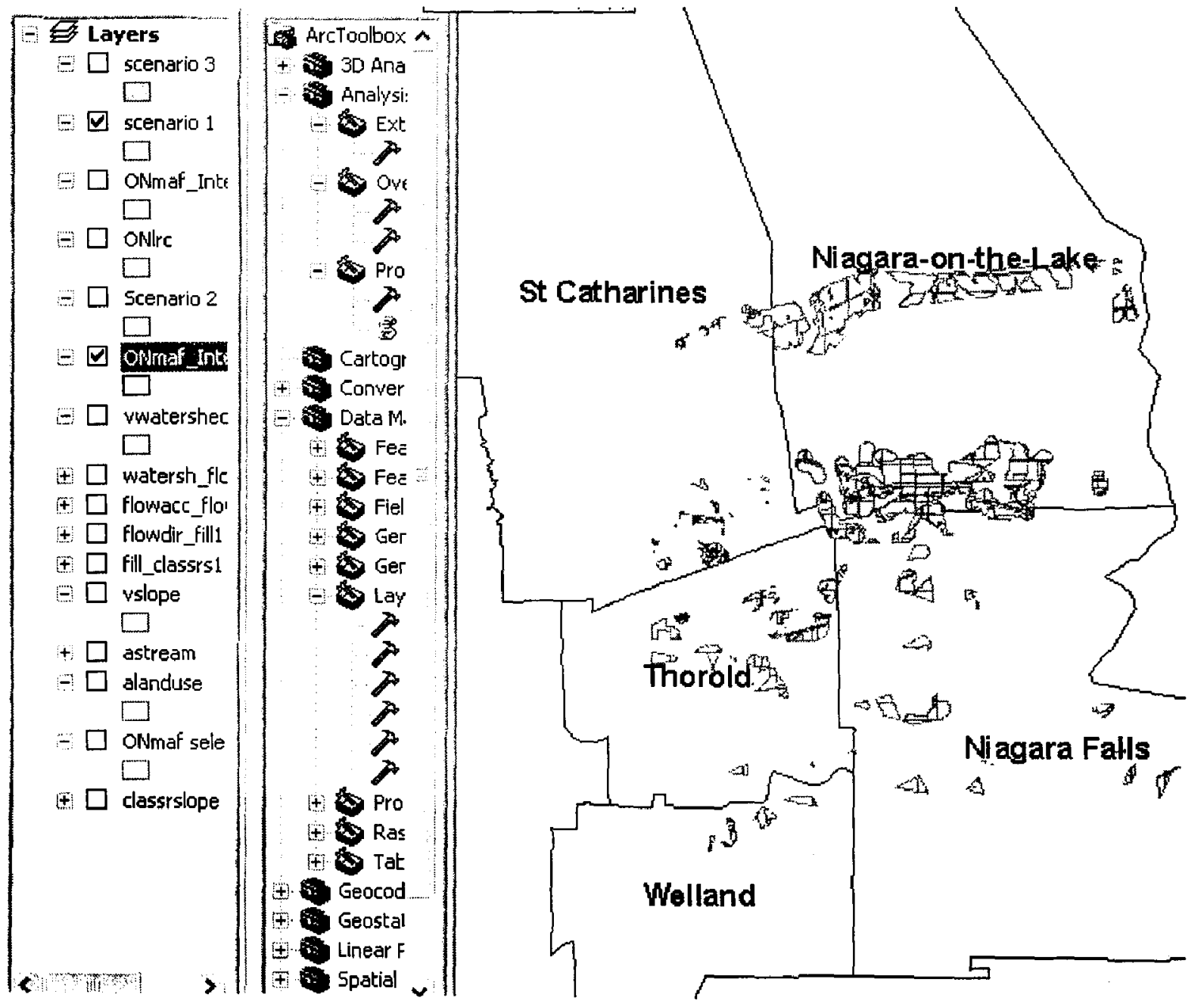

Figure 16 Vulnerable sites for Scenario I 
Scenario II: In the second scenario, the slope is changed in between 1-3 degree and the buffer distance remains the same as 300 meter. In this case as the value of the slope is not too high, the amount of run-off which basically contains the agricultural chemicals, come from the area of this slope will also be little, drain into the stream surfaces. The run-off infiltrates to the area of this slope which ultimately led to less contamination compare to the original model. So the agricultural lands that are located on these slopes and within stream buffer are not very significantly responsible for the contamination. So, to take the protection measures in this area will not be appropriate decision. Figure 17 shows the display map for this scenario.

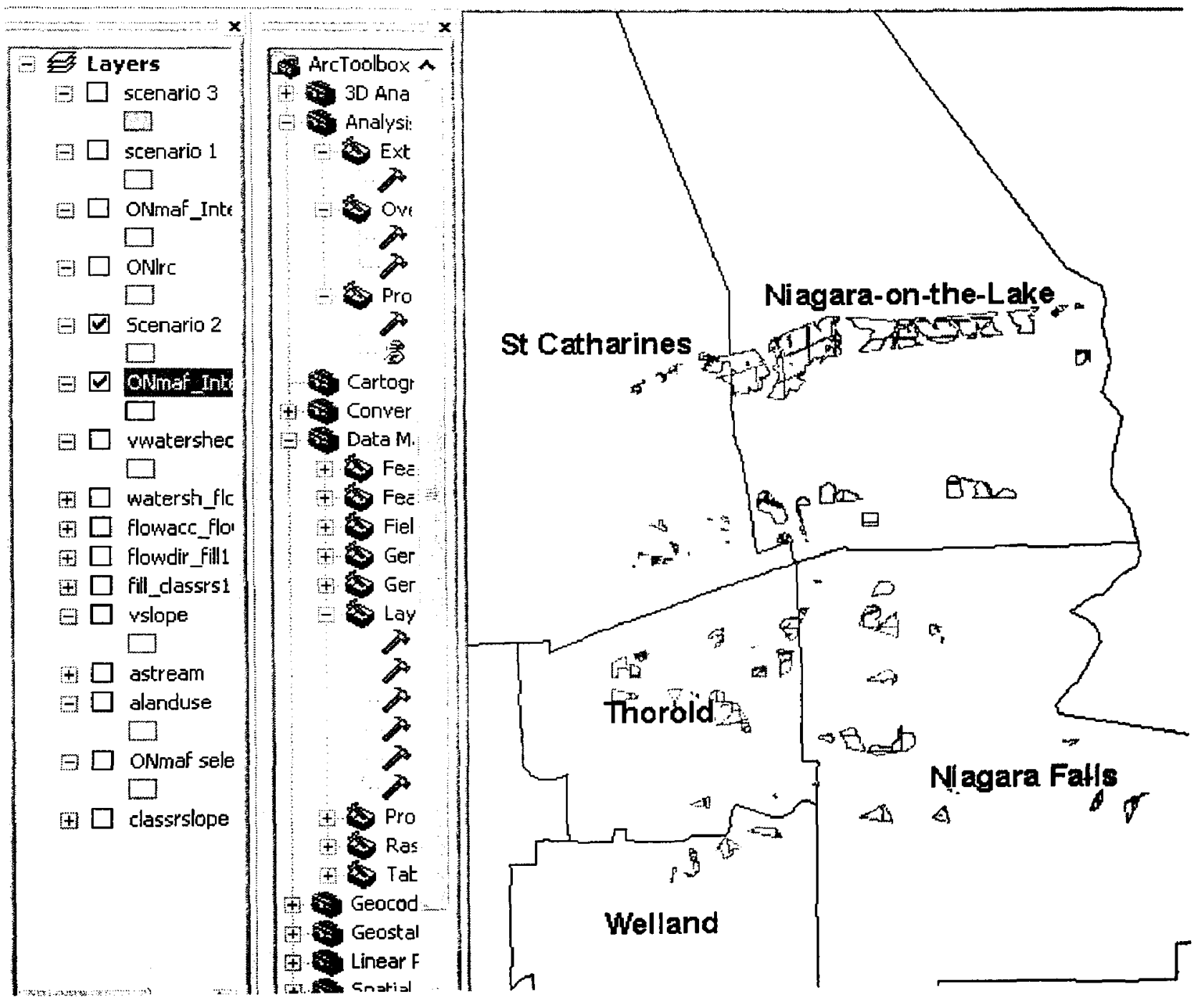

Figure 17 Vulnerable sites for Scenario II 
Scenario III: In this scenario, the slope value lies between 10-15 degree and the buffer distance remain as the original value. In this case, the agricultural land that is located on this most steepslopes not much remarkable. That is why contaminated area is less than that found in areas lies between 5-10 degree slopes. Figure 18 shows the display map for this scenario.

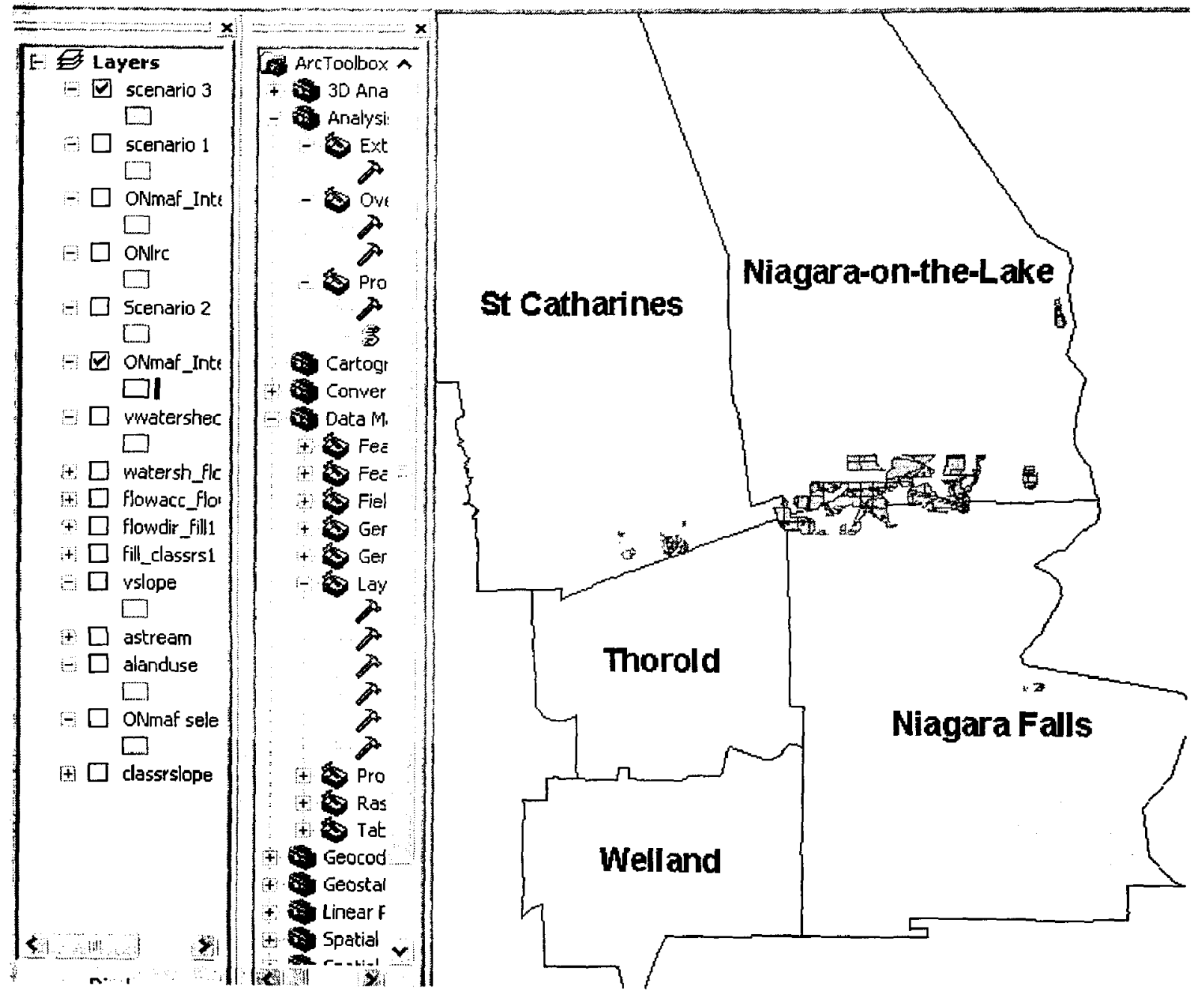

Figure 18 Vulnerable sites for Scenario III 


\subsection{Comparison Table}

The study solved various tasks with different scenario on the model builder process. Table 5 below listed the quantity of contaminated area and a statistics associated with different alternatives.

Table 5 Contaminated areas associated with different alternatives

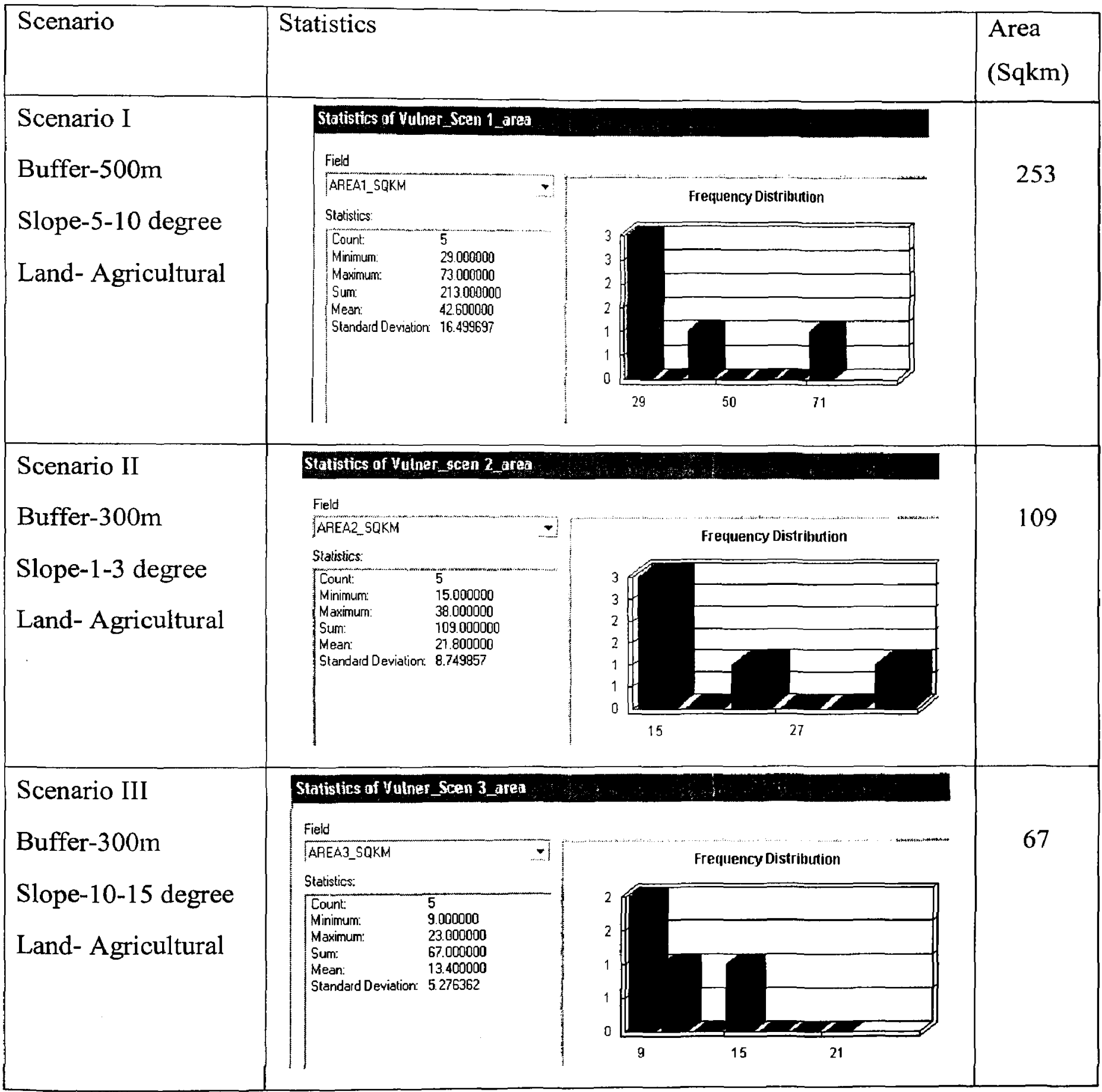




\subsection{Results}

The value of two parameters slope and the stream buffer distance are defined from MOE (Ministry of Environment) guidelines. 300 meter buffer distance and 5 to 10 degree slope value is most appropriate value for the groundwater protection model as we see on the comparison table that steeper slope giving less contaminated area.. The resulting feature class added to the map (see Figure 19) and to highlight the identified areas, the model results layer (named vulnerable layer) is given a suitable colour to view clearly.

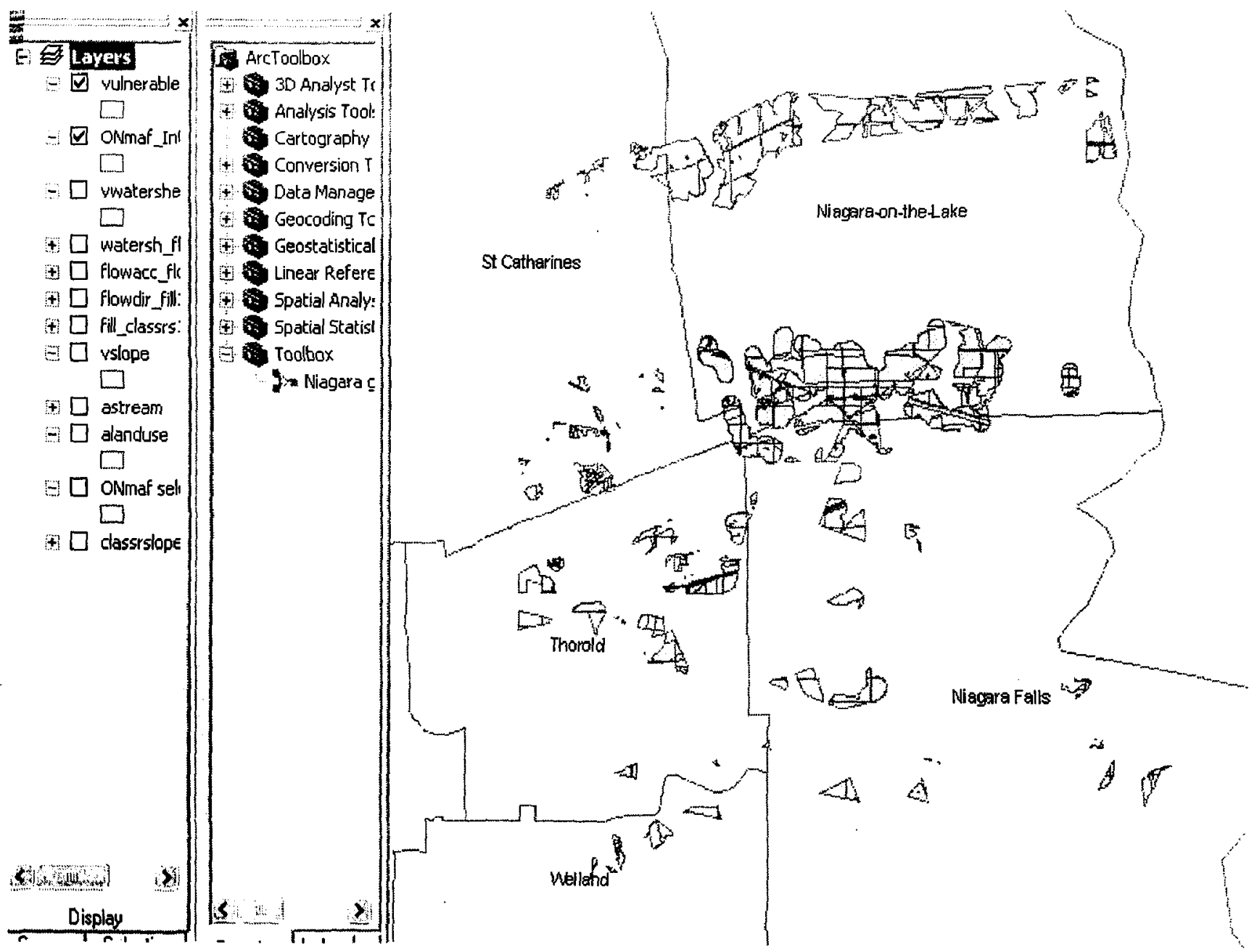

Figure 19 Vulnerable site

In the model green areas of results layer are the most vulnerable site for contamination. After getting the model output, the model_results will be validated. The information about the study 
area will be collected as the area is really affected with agricultural contaminants and then match with the identified areas and taken remediation measures.

\subsection{Discussion}

Natural systems (for example, biological, geological, and ecological systems) and their relevant phenomena are very complex; therefore, it is practically impossible to model such systems perfectly, and of these models requires simplification and approximation. Modeling efforts cannot give positive answers if data about the physical system being modeled are not properly taken into account at every stage of the model development. So, the data accessibility is fundamental issues in terms of sources of data; data collection, conversion, and integration, and also data capture cost and time for environmental modeling applications using GIS tools.

In Arc GIS the Model Builder interface provides a graphical modeling framework for designing and implementing geoprocessing models that can include tools, scripts, and data. The data required for developing groundwater protection model and analyses of this project are slope data, stream data, watershed data, and agricultural data. In this regard the types of data collected are DEM data, land use data, stream data, and municipal boundary data. Actually it takes more time to arrange these data based on project requirements comparative with the model development processing time. The watershed data and slope data are created from the DEM data and the

agricultural data from land use data. So, it is required to convert the DEM data and integrate all of these data to perform the desired operations.

Digital Elevation Models (DEM) is data files that contain the elevation of the terrain over a specified area, usually at a fixed grid interval over the surface of the earth. The intervals between each of the grid points will always be referenced to some geographical coordinate system. This is usually either latitude-longitude or UTM (Universal Transverse Mercator) coordinate systems. DEMs come in different scales and resolutions. The closer together the grid points are located, the more detailed the information will be in the file. The details of the peaks and valleys in the terrain will be better modeled with small grid spacing than when the grid intervals are very large. Elevations other than at the specific grid point locations are not contained in the file. The DEM file also does not contain civil information such as roads or buildings. The DEM does not contain elevation contours, only the specific elevation values at specific grid point locations. 
In the physical sense, the notion of scale refers to the resolution, defined by equivalent length or area that represents scaled field reality. In a GIS, analysis is done at the resolution of the data, not at any display scale. Resolution is the degree to which closely related entities can be discriminated. Resolution also limits the minimum size of feature that can be stored. Raster data is stored as (usually square) pixels, which form a grid or mesh over an area of the earth. The size of these pixels determines the resolution of the raster, because it is impossible to store anything which falls 'between' the pixels.

In this project the DEM data are obtained from GeoBase at a scale of 1:50,000. The rest of the data were acquired from Can Map Route Logistics 2005.3 (Ontario) through Ryerson University Library Geospatial Resources at the same scale. The scale 1:50,000 is accepted as it is a very large scale because the larger the scale, the more the detail described by the map and with higher accuracy. So, it is not necessary to change the scale.

To develop the model all dataset should be converted to personal geodatabase. In ArcGIS, Arc Toolbox is embedded in Arc Map and Arc Catalog. Arc Toolbox contains a comprehensive collection of geoprocessing functions; among these functions data conversion is most fundamental. Using the data conversion tools the DEM data is ultimately converted as per required to slope raster data, polygon data, and then find watershed data using hydrology tools. The dataset in this stage appears in same format as vector format. The Arc Catalog application organizes and manages all GIS information such as maps, globes, data sets, models, metadata, and services. All vector dataset then converted to personal geodatabases using Arc Catalog. The personal geodatabse is finally used to model development.

In the model_result layer which is displayed in Arc Map, the highlighted areas are most vulnerable to contamination. In the process model by setting the SQL expression parameter for the Make Feature Layer tool as a variable and exposing it as a model parameter. By replacing the expression with different parameter value, various analyses are done and compare with the original model. So, from analyses it can be said the effort to build the model with the parameter such as slope value and buffer distance around stream are 5 to 10 degree and 300 meter are most appropriate for taking protection control measures in the study area. 


\section{CONCLUDING REMARKS}

Today, agriculture in Ontario is among the most efficient in the world, with low production costs and high safety and quality standards. Niagara is an integral part of the Ontario agricultural economy. Historically agriculture provided an impetus for growth in the area and it continues to sustain a significant component of the Niagara economy. In 2001, the Niagara agri-food industry contributed $\$ 32.1$ billion to Ontario's economy, employed more than 650,000 people across the province and exported $\$ 7.8$ billion of agricultural products around the world, a $13.5 \%$ rise over the previous year (Census of Agriculture, 2001).

The agricultural practices are severely responsible for contaminating air and water quality in this region. Agricultural practices have an effect on the levels of GHG (Green House Gases) in the atmosphere. The link between farming and the quality of surface and ground water has become an important environmental and health issue. Most farmers in this area do not have access to use municipal water; therefore use of groundwater for irrigation is common. Theoretically, there is unused capacity within the regional aquifers as the current use is only $15 \%$ of the recharge at regional level (Regional Municipality of Niagara, 2003). The bed rock wells in this region do not contain good water qualities. Agricultural inputs such as fertilizer. livestock manure, and pesticides have caused water contamination when improperly stored, applied or disposed of. There is also concern that certain bacterial, nitrate. and high sulfur concentrations exceed drinking water guidelines in surface or groundwater, there may be negative health effects. So, it is now evident that ground water is seriously vulnerable to pollution and depletion due to anthropogenic activities in this region. As water quality affects Niagara's economy. Peoples need clean water for production and for drinking purpose. Property values can decrease near waterways that are heavily contaminated. A decrease in water quality also means an increase in the cost of water treatment for human use. But the agricultural land of Niagara cannot be replaced: it is amongst the best of a limited supply.

Groundwater must be protected since ground water is an integral part of the water cycle and it will carry contaminants and pollutants from the land into the lakes and rivers from which other people get a large percentage of their freshwater supply. In dry periods, the flow of some streams may be supplied entirely by groundwater. Protecting the ground water from contamination will require 
thoughtful management and cooperation on the part of citizens and various levels of government. Land use planning is, in many cases, the best instrument available for protecting aquifers which still contain good quality water. If potential sources of contamination are kept from locating over critical recharge areas, the risk of contamination can be greatly reduced. Industries, farmers, and homeowners located over ground water supplies need to practice good housekeeping with respect to the use and disposal of chemicals. In order to combat water pollution, it is necessary to locate the most vulnerable areas of a watershed.

In recent years, considerable interest has been focused on the use of GIS as a decision support system. The use of GIS as a direct extension of the human decision making process-most particularly in the context of resource allocation decisions is indeed a great challenge and an important milestone. The conventional way of most study is less accurate and more timeconsuming process as it has more dependent and independent variables. But GIS can handle the larger volume of spatial $\&$ non-spatial data and which is capable of doing complex analysis. GIS is the latest technology and tool, which can produce much more accurate results quickly \& effectively.

Spatial Decision Support Systems (SDSS) are a computer-based system designed to assist decision making. Typically, such a system will include spatial data relevant or the decisions, analytic tools to process the data in ways meaningful for decision makers, and output or display functions. Thus, an SDSS has considerable overlap with the functionality of a geographic information system (GIS).According to the National Centre of Geographic Information and Analysis (NCGIA) Core Curriculum in Geographical Information Systems, an SDSS is an "interactive, computer-based system designed to support a user or group in achieving a higher effectiveness of decision making while solving a semi-structured spatial decision problem". There are many examples of SDSSs for specific decisions in the environmental domain, particularly in the areas of crop, livestock. flood, and forest management.

Spatial decision support tools require environmental models both as sources of data and as key tools to guide decision making. An SDSS requires delivery of at least some foundation data, as the expertise needed to create and assemble these data is high and the transaction costs of doing so steep, but the opportunity to pay this cost only once is of enormous benefit to multiple users. Besides providing foundation data and a core tool set, key features of the SDSS include link to 
auxiliary database and documentation, and the ability to incorporate additional, applicationspecific tools, including various types of highly specific, tailored, environmental models.

Models are a particularly useful addition to Arc GIS. Arc GIS Desktop provides a geoprocessing framework of tools that can be run in several different ways, including through dialog boxes in Arc Toolbox, as inputs to models in Model Builder, as commands in the command line, and as functions in scripts. This framework facilitates the creation, use, documentation, and sharing of geoprocessing models. The two main parts of the geoprocessing framework include Arc Toolbox, an organized collection of geoprocessing tools. and Model Builder. a visual modeling language for building geoprocessing work flows and scripts.

This report developed a groundwater protection model using Model Builder Window of ArcGIS 9 and discussed how identify the steep-sloped agricultural fields of the study area which is susceptible to contaminate the groundwater by agricultural chemicals through precipitation and which is discharged in springs, streams, lakes. or wetlands. It did not address the issues related to the policy level. Improved management practices and a proper Nutrient Management Plans (NMP) can be applied in that area that can help to protect ground water contamination. Specific practices, which include prudent livestock and manure handling, balanced use of fertilizer, fuel, pesticides, and sustainable soil management will enhance water quality. Further environmental investigations, including secondary source reviews and ficld investigations will be required to generate best vulnerable areas, assess the impacts and best management practices.

Finally, some recommendations can be established as follows:

- The agricultural land is a non- point source of groundwater contamination in Niagara.

- Once the aquifers are contaminated they become very difficult and costly to remedy and in most cases are abandoned. Protecting groundwater resources from pollution is therefore essential for its proper management and preventing probable hazards.

- In this regard ArcGIS 9 provides new tools to build protection model to study groundwater contamination issues of various watersheds that performs multiple geoprocessing operations.

- In this project the intention of the protection model is to define the areas of the study areas where the run-off from the steep-sloped crop fields is one likely source of groundwater contamination by agricultural chemicals. 
- Areas defined through the groundwater protection model are most vulnerable to contamination of groundwater as the run-off infiltrate through different soils and possibly recharge an aquifer or contribute water to a pathway delivering water to an aquifer. Groundwater recharge is the portion of infiltrating water that will move downward through the unsaturated zone. When infiltration reaches the water table it becomes groundwater recharge. Recharge replenishes water in aquifers, or is discharged in springs, streams, lakes or wetlands.

- Assessing the quality of a model is called validation. Model validation is possibly the most important step in the model building sequence. So, in this study the information about the study area will be collected as the area is really affected with agricultural contaminants and then match with the identified areas and taken remediation measures.

- Different analyses should be done to change the value of parameters of the model and compare with the original model. After analyses effective decisions from the model output are taken.

- After developing the final groundwater protection model of the study area the improved management practices and a proper Nutrient Management Plans can be applied in that area that can help to sustain.

- For further study the model and its process can be modified and adapted for other studies as for example to investigate the potential sources of runoff from petroleum products in a watershed. 


\section{REFERENCES}

Agriculture Canada, 1994, Water Management - Best Management Practices, Ministry of Agriculture and Food, Ontario.

Arnold, J.G. et al, 1998, Large Area Hydrologic Modelling and Assessment, Part I: Model

Development, Journal of the American Water Resources Association, Vol. 34, No. 1, Feb.

Bierkens, M. and C.E.Puente, 1990, Analytically derived runoff models based on rainfall point processes.

Burnett, P. et al, 1997, On the Origin of the Oak Ridges Moraine.

Carlotto, M. J., 1995, "Detection and Analysis of Change in Remotely Sensed Imagery with Application to Wide Area Surveillance".

Clarke, C. and O. Bradley, 2002, Geographic Information Systems and Environmental Modeling.

Corkal D., 2002, Rural Water Safety From The Source To The On-Farm Tap. Drinking Water Safety: A Total Quality Management Approach, International conference on water and health. Ottawa.

David, R. and G. Payne, 1995, Groundwater Supplies in Ontario, p.93.

Donigian, J. and W. Huber, 1991, Modelling of Non-Point Source of Water Quality in Urban and Non-Urban Areas,

Environment Canada, 2001.

Environment Canada, 1992, Water - Nature's Magician, - Here, There and Everywhere, - etc., Freshwater Series.

Environment Canada, 1997, HYDAT - Surface Water and Sediment Data.

Environmental Systems Research Institute (ERSI) Inc., 1997, ArcDoc, Online, Ver. 7.1.

ESRI, 2004, What is ArcGIS.

Feenstra, B.H., 1981, Quaternary Geology and Industrial Minerals of the Niagara -Welland Area, Southern Ontario, Ontario Ministry of Natural Resources. 
Fetter, C. W., 1999, Contaminant Hydrogeology, Second Edition, Prentice Hall Inc.

Final Report of the NPCA Ground Water Study, 2005, Waterloo Hydrogeologic Inc.

Fisher, H.T., 1982, Mapping information: the graphic display of quantitative information. Cambridge.

Gartner, L., 1987, The Highland Creek and Rouge River Pollution Study, Volume 1.

Harmancioglu, N.B., O. Fistikoglu, 1998, Water Quality Monitoring Network Design, Kluwer Academic Publishers, Dorbrecht, The Netherlands.

Heuvelink, G.B.M. and M.F.P. Bierkens, 1992, Combining Soil Maps with Interpolations from Point Observations to Predict Quantitative Soil Properties.

Katsifarakis, K.L., 2001, Groundwater Pollution Control.

Kite, G. W. et al, 1996, GIS for Large Scale Watershed Modelling, Kluwer.

Lee, D., 1991, Determination of Geo-Chemical Modification of Groundwater Entering Surface Water from an Industrial and Municipal Disposal Site, MOE Research Study.

Legates, D. R. and C. J. Willmott, 1994, Evaluating Water Balance from Historical Climatic Records.

Lempert, M. and M. W. Ostrowski, 1997. GIS Based Grid Cell Model for Water Balance Simulations, Institute of Hydraulic and Water Resources Engineering, Darmstadt University of Technology.

Lloyd J.W. and J.A. Heathcote, 1985, Natural inorganic hydrochemistry in relation to groundwater, Claredon Press, Oxford.

Maidment, D. R., 1991, GIS and Hydrological Modelling, Oxford University Press, New York.

Ministry of Natural Resources, 1984, Water Quantity Resources of Ontario, MNR Publication.

Ministry of the Environment, Province of Ontario, Canada

MOE, 1980, Ground Water Resources in the Grand River Basin.

MOE, 1995, Water Wells and Ground Water Supplies in Ontario. 
Monthly Niagara Farmers' published by Niagara Restoration Council.

Muller, R. M. and J. Middleton, 1994. A Markov model of land-use change dynamics in the Niagara region, Ontario, Canada, Landscape Ecology 9, 151-157.

O'Connor, D., 2002, A Strategy for Safe Water- Part two, Report of the Walkerton Inquiry, Queens Printer, Toronto, ON.

Ongley E., 1997, Guidelines on Water and Sustainable Development: Principles and Policy, UN Water Resources Series No. 77. $136 \mathrm{p}$.

Ontario Groundwater Association, 1998, Groundwater Data and Management in Southern Ontario. Ontario Ministry of Environment, 1995, Water Wells and Groundwater Supplies in Ontario, Ontario Ministry of Environment, 2000, Drinking Water Information Management System, (DWIMS).

Overview of Regional Municipal Niagara, 1999, MacViro Consultants Ltd.

Puente, C.E., Dik, P.E., 1993, Practical use of analytically derived runoff models based on rainfall point processes, Water Resources Research 29(10),

Singh, V.P. and Fiorento, M., 1996, Geographical Information Systems in Hydrology, Kluwer.

U.S. Environmental Protection Agency. Washington DC, USA.

Ullman, J.D., 1988, Principles of database and knowledge-base systems, Computer Science Press, Rockville, Md.

Zemo, D. A., and T. E. Graf, 1995, The application of Petroleum Hydrocarbon Fingerprint Characterisation in Site Investigation and Remediation, Ground Water Monitoring and Remediation, Vol. 15, No 2. 